\title{
Sigmatropic rearrangements of cyclopropenylcarbinol derivatives. Access to diversely substituted alkylidenecyclopropanes
}

\author{
Guillaume Ernouf ${ }^{1}$, Jean-Louis Brayer ${ }^{2}$, Christophe Meyer ${ }^{* 1}$ and Janine Cossy ${ }^{* 1}$
}

\author{
Review \\ Address: \\ ${ }^{1}$ Laboratory of Organic Chemistry, Institute of Chemistry, Biology, \\ Innovation (CBI), ESPCI Paris, CNRS (UMR 8231), PSL Research \\ University, 10 rue Vauquelin, 75231 Paris Cedex 05, France and \\ ${ }^{2}$ Minakem, Parc Naturel Régional Scarpe-Escaut, 145 chemin des \\ lilas, 59310 Beuvry-la-Forêt, France \\ Email: \\ Christophe Meyer ${ }^{*}$ - christophe.meyer@espci.fr; Janine Cossy ${ }^{*}$ - \\ janine.cossy@espci.fr \\ * Corresponding author \\ Keywords: \\ alkylidenecyclopropanes; cyclopropanes; cyclopropenes; sigmatropic \\ rearrangements; strained rings \\ Beilstein J. Org. Chem. 2019, 15, 333-350. \\ doi:10.3762/bjoc. 15.29 \\ Received: 22 October 2018 \\ Accepted: 08 January 2019 \\ Published: 05 February 2019 \\ This article is part of the thematic issue "Cyclopropanes and \\ cyclopropenes: synthesis and applications".

\section{Guest Editor: M. Tortosa} \\ (C) 2019 Ernouf et al.; licensee Beilstein-Institut. \\ License and terms: see end of document.
}

\begin{abstract}
Cyclopropenes constitute useful precursors of other classes of compounds incorporating a three-membered ring. Although the transformation of substituted cyclopropenes into alkylidenecyclopropanes can be accomplished through different strategies, this review is focusing specifically on the use of [2,3]- and [3,3]-sigmatropic rearrangements involving cyclopropenylcarbinol derivatives as substrates. These sigmatropic rearrangements, which have been developed in recent years, allow a remarkably efficient and stereoselective access to a wide variety of heterosubstituted and/or functionalized alkylidenecyclopropanes which would not be readily accessible by other strategies. The different [2,3]- and [3,3]-sigmatropic rearrangements of cyclopropenylcarbinol derivatives disclosed to date, as well as the analysis of their substrate scope and some applications of the products arising from those reactions, are presented in this review.
\end{abstract}

\section{Introduction}

Among the ever expanding diversity of chemical transformations involving cyclopropenes, which are largely dominated by ring-cleavage processes to access functionalized acyclic compounds or to construct new carbocycles or heterocycles, those reactions that preserve the three-membered ring and enable

access to diversely substituted cyclopropanes or alkylidenecyclopropanes are also synthetically useful [1-6]. The importance of this latter class of transformations is obviously related to the widespread occurrence of cyclopropanes in natural and/or bioactive compounds $[7,8]$ and the great interest of the cyclo- 
propyl core in new drugs development [9]. Alkylidenecyclopropanes also constitute another important class of strained carbocycles displaying a versatile chemistry owing to their multiple reactive sites (the exocyclic olefin and the proximal and distal bonds on the ring) [10-15]. Although the synthesis of alkylidenecyclopropanes can be achieved by many different routes, controlling the configuration of the exocyclic olefin as well as that of stereocenters on and adjacent to the three-membered ring remains a challenging task [15]. In this context, cyclopropenes can serve as useful precursors of substituted and functionalized alkylidenecyclopropanes. The transformation of cyclopropenes into alkylidenecyclopropanes has been achieved through different strategies (Scheme 1). The first one relies on the isomerization of the olefin in alkylcyclopropenes $\mathbf{A}$ from the endocyclic to the exocyclic position (Scheme 1, reaction 1) [16-18]. Owing to the relief of ring-strain, the formation of the alkylidenecyclopropane $\mathbf{B}$ is generally thermodynamically favored $[19,20]$. However, in the particular case of gem-difluorocyclopropenes $\mathbf{A}^{\prime}\left(\mathrm{R}^{3}=\mathrm{R}^{\prime 3}=\mathrm{F}\right)$ which possess a cyclopropenium (aromatic) character, the position of the equilibrium depends on the substituent at $\mathrm{C} 1$. Whereas conjugation with the phenyl group $(\mathrm{R}=\mathrm{Ph})$ provides the driving force for the basepromoted isomerization of 1-benzyl-3,3-difluorocyclopropene (A', R = Ph) into the corresponding benzylidene(gem-difluorocyclopropane) (B') [18], methylene(gem-difluorocyclopropane) (B', $\mathrm{R}=\mathrm{H}$ ) is isomerized into 1-methyl-3,3-difluorocyclopropene (A") [21] (Scheme 1, reaction 1). Another approach relies on the reaction of cyclopropenylmethyl organometallic species $\mathbf{C}$ with electrophiles through an $\mathrm{S}_{\mathrm{E}} 2$ ' process leading to substituted alkylidenecyclopropanes D (Scheme 1, reaction 2). Examples of those transformations include the carboxylation of a (trimethylsilylmethyl)cyclopropene in the presence of a fluoride promoter [22], and also the addition of electrophiles to (lithiomethyl)cyclopropenes generated by lithiation of the corresponding methylcyclopropenylsulfone [23] or -sulfoxide [24]. More recently, the addition of cyclopropenylmethylboronates to aldehydes was also reported [25]. A complementary strategy involves the addition of nucleophiles, in particular organometallic reagents, to cyclopropenylcarbinols or their derivatives $\mathbf{E}$, which leads to alkylidenecyclopropanes $\mathbf{F}$ through a formal $\mathrm{S}_{\mathrm{N}} 2$ ' process (Scheme 1, reaction 3) [23,26-33]. Thus, methylenecyclopropanes have been prepared by diastereoselective addition of Grignard reagents to cyclopropenylmethyl ethers, possessing a hydroxymethyl directing substituent at C3, in the absence or in the presence of a catalyst (copper or iron salt) [28-30]. Another representative transformation is the coppercatalyzed addition of Grignard reagents to secondary unprotected cyclopropenylcarbinols which proceeds with high levels of chirality transfer to afford alkylidenecyclopropanes possessing a quaternary stereocenter at C2 [31,33]. In this review, we shall exclusively focus on alternative strategies that rely either on a [2,3]-sigmatropic rearrangement (Scheme 1, reaction 4) or a [3,3]-sigmatropic rearrangement of cyclopropenylcarbinol derivatives (Scheme 1, reaction 5). These transformations have emerged as useful tools over the past few years to access hetero-substituted and/or functionalized alkylidenecyclopropanes.

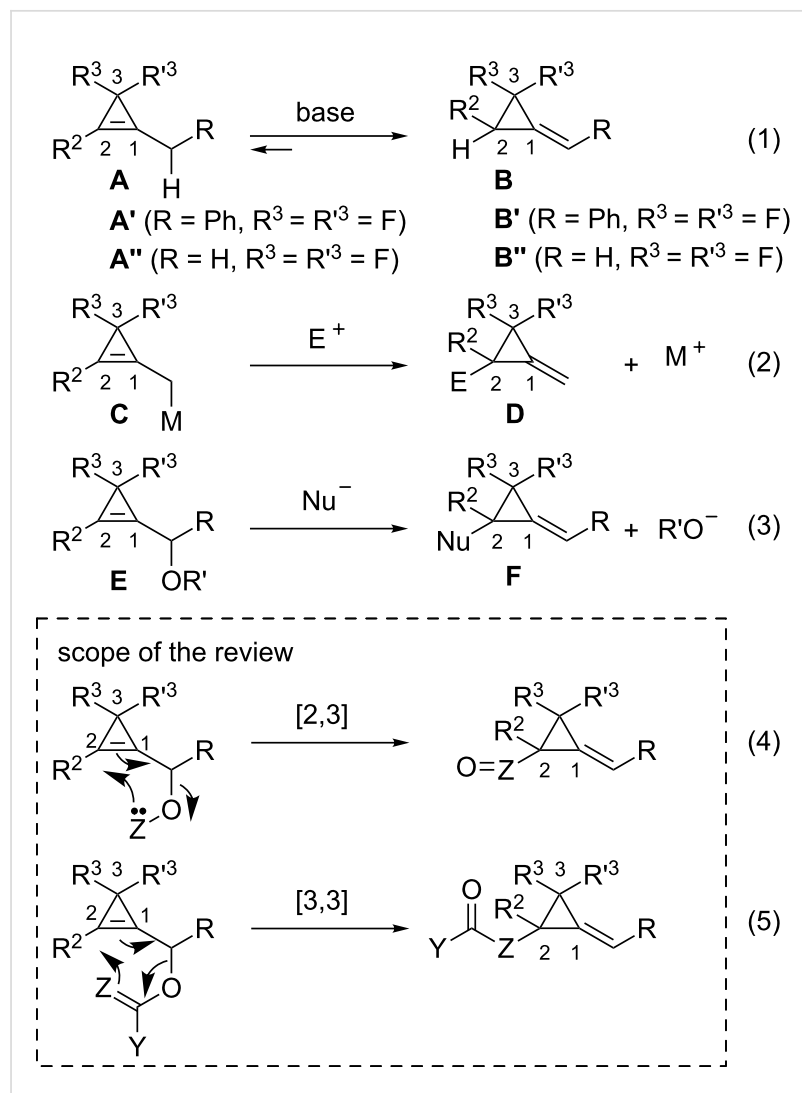

Scheme 1: Representative strategies for the formation of alkylidenecyclopropanes from cyclopropenes and scope of the review.

\section{Review}

\section{$[2,3]$-Sigmatropic rearrangements involving cyclopropenylcarbinol derivatives}

Following their report on the synthesis of chiral alkylidenecyclopropanes by copper-catalyzed addition of Grignard reagents to enantiomerically enriched cyclopropenylcarbinols [31], Marek et al. investigated other classes of transformations involving those latter strained analogs of allylic alcohols as substrates. In 2007, the [2,3]-sigmatropic rearrangement of cyclopropenylcarbinyl phosphinites was reported as a route to chiral phosphines possessing an alkylidenecyclopropane backbone [34]. The starting cyclopropenylcarbinols were readily prepared by addition of the corresponding cyclopropenyl organolithium reagents, generated in situ by treatment of 1,1,2-tribromocyclopropane with $n$-butyllithium (2 equiv) [35], to various aldehydes and ketones. Marek et al. observed that the treatment 
of cyclopropenylcarbinols 1a-h with chlorodiphenylphosphine in the presence of triethylamine (THF, rt) resulted in a very rapid formation of (alkylidenecyclopropyl)diphenylphosphine oxides 3a-h (85-94\%), resulting from an efficient [2,3]-sigmatropic rearrangement of the in situ-generated phosphinites $\mathbf{2 a - h}$. Primary or tertiary cyclopropenylcarbinols reacted equally well, as shown with the formation of phosphine oxides $\mathbf{3 a}(94 \%), \mathbf{3 b}$ $(93 \%)$ and $3 \mathbf{c}(87 \%)$. The [2,3]-sigmatropic rearrangement of phosphinites $\mathbf{2 d - h}$ derived from secondary cyclopropenylcarbinols led to the corresponding phosphine oxides $\mathbf{3 d}-\mathbf{h}$ (85-93\%) as a 80:20 mixture of $E / Z$ geometric isomers, regardless of the substituent of the alcohol (at C4) and of the cyclopropene (at C2, Scheme 2) [33,34].

The [2,3]-sigmatropic rearrangement of an optically enriched phosphinite $\mathbf{2 f}$, prepared from the corresponding secondary cyclopropenylcarbinol $(S)$-1f $($ ee $=99 \%)$, which in turn is readily available by applying the Sharpless kinetic resolution procedure to $( \pm)$-1f [31], was also investigated. The resulting geometric isomers $(Z)$-3f and $(E)$-3f, which were separated by flash chromatography, were found to possess optical purities identical to that of the parent substrate $(S)$-1f (ee $=99 \%$ ) thereby confirming that complete chirality transfer occurred (from $\mathrm{C} 4$ to $\mathrm{C} 2$ ) during the [2,3]-sigmatropic rearrangement $[33,34]$. It is also worth mentioning that the absolute configuration of $(Z)-\mathbf{3 f}$ and $(E)-\mathbf{3 f}$, which is opposite at $\mathrm{C} 2$, was assigned by comparison of their computed and experimentally observed CD spectra $[33,34]$. To tentatively explain the observed stereochemical outcome in the absence of additional knowledge on the transition state of the rearrangement [36], two reactive conformers $\mathbf{G}$ and $\mathbf{G}$ ' were considered which would lead to five-membered ring transition states in which the aryl group occupies a preferential pseudo-equatorial or a less favorable pseudo-axial orientation, respectively (Scheme 3) [33,34].

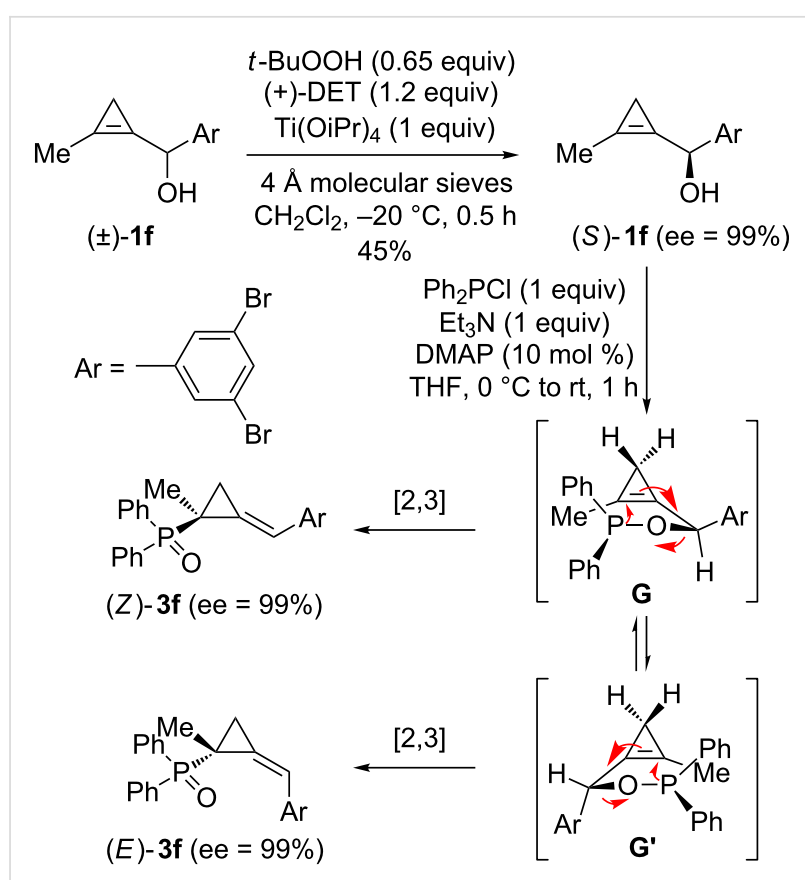

Scheme 3: [2,3]-Sigmatropic rearrangement of a phosphinite derived from enantioenriched cyclopropenylcarbinol $(S)-1 f$.

The authors also showed that phosphine oxide $(E)$-3f could be reduced to the corresponding phosphine 4 (94\%) by treatment with trichlorosilane, without affecting the (arylmethylene)cyclopropane moiety (Scheme 4).

The great efficiency of the [2,3]-sigmatropic rearrangement of phosphinites $\mathbf{2 a}-\mathbf{h}$ lacking substituents at $\mathrm{C} 3$ is in striking contrast with the reactivity of phosphinites possessing a geminal disubstitution at C3. In 2007, Rubin et al. reported their results on the [2,3]-sigmatropic rearrangement of cyclopropenylmethyl phosphinites derived from primary cyclopropenyl-

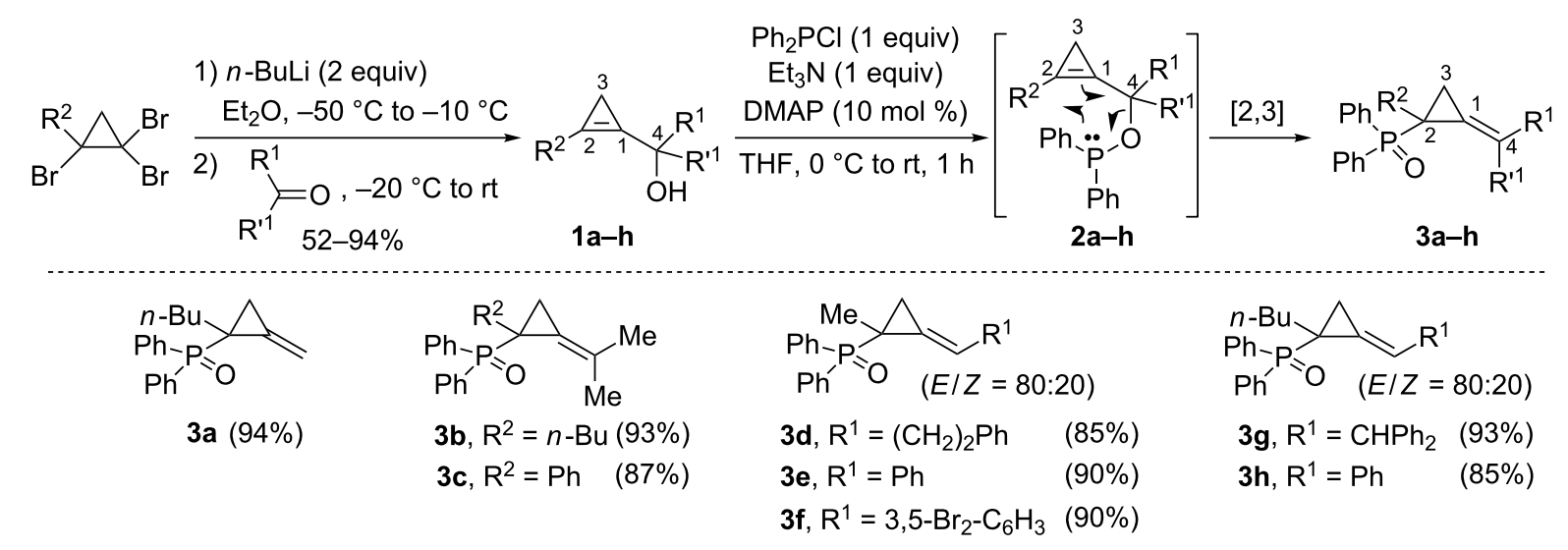


<smiles>CC1(P(=O)(c2ccccc2)c2ccccc2)CC1=Cc1cc(F)cc(Br)c1</smiles>

(E)-3f

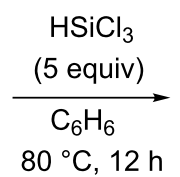

$80{ }^{\circ} \mathrm{C}, 12$

Scheme 4: Selective reduction of phosphine oxide $(E)-3 f$.

carbinols [37]. As illustrated in the case of 5a, the substrates were prepared from the tert-butyldimethylsilyl (TBS) ether of propargyl alcohol by a rhodium-catalyzed cyclopropanation with an aryldiazoacetate followed by reduction of the ester moiety and protecting group manipulation. Phosphinite 6a, generated from alcohol 5a under standard conditions, did not undergo a [2,3]-sigmatropic rearrangement into the corresponding diastereomeric phosphine oxides $\mathbf{7 a} / \mathbf{7}$ 'a, even upon prolonged heating (toluene, $110^{\circ} \mathrm{C}$ ), and underwent slow decomposition instead (Scheme 5).

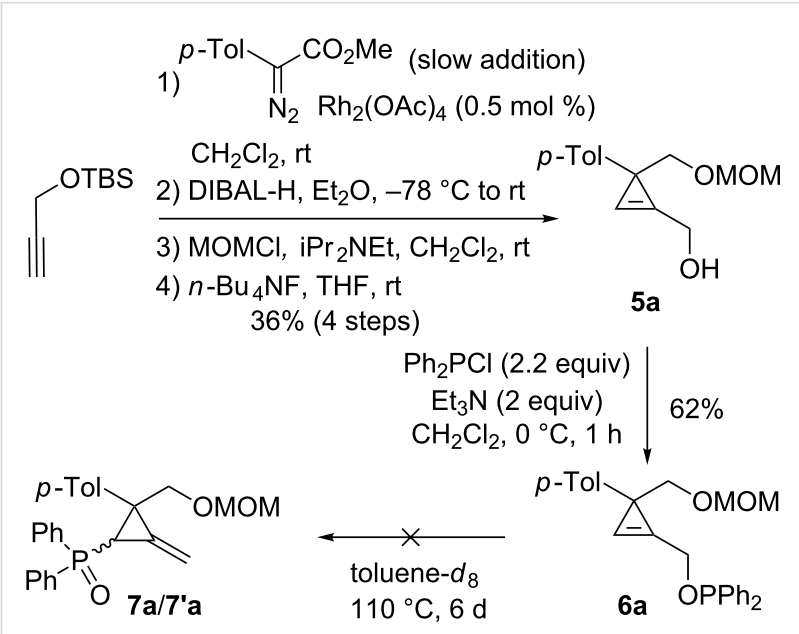

Scheme 5: Attempted thermal [2,3]-sigmatropic rearrangement of phosphinite $6 \mathbf{a}$.

This observation was in agreement with DFT calculations which indicated that the rearrangement of cyclopropenylmethyl phosphinite I, although thermodynamically favored, displays a high activation barrier compared to that of the acyclic allyl analog $\mathbf{H}$. An even higher activation barrier was calculated in the case of the 3-methyl and 3-phenyl-substituted cyclopropenes, I' and I', respectively, which indicates that the concerted [2,3]-sigmatropic rearrangement would require high temperatures incompatible with such thermally labile strained substrates (Scheme 6) [37].

Interestingly, the authors detected traces of methylenecyclopropanes $7 \mathbf{a} / 7$ 'a when phosphinylation of alcohol $\mathbf{5 a}$ was con-

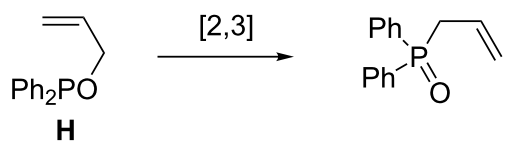

$\Delta G^{\ddagger}=31 \mathrm{kcal} / \mathrm{mol}, \Delta G=-18 \mathrm{kcal} / \mathrm{mol}$

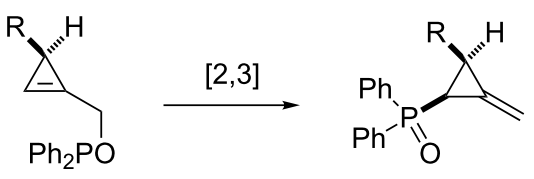

I, $\mathrm{R}=\mathrm{H}, \Delta \mathrm{G}^{\ddagger}=25 \mathrm{kcal} / \mathrm{mol}, \Delta \mathrm{G}=-34 \mathrm{kcal} / \mathrm{mol}$

I', $\mathrm{R}=\mathrm{Me}, \Delta \mathrm{G}^{\ddagger}=30 \mathrm{kcal} / \mathrm{mol}$

l", $\mathrm{R}=\mathrm{Ph}, \Delta \mathrm{G}^{\ddagger}=37 \mathrm{kcal} / \mathrm{mol}$

Scheme 6: Computed activation barriers and free enthalpies

ducted at room temperature for several hours which led them to consider that the amine could play a role in promoting the [2,3]sigmatropic rearrangement. After a screening of different tertiary amines, Rubin et al. found that DBU could be used as a base in the phosphinylation reaction but also as an efficient catalyst for the subsequent [2,3]-sigmatropic rearrangement of phosphinite 6a which afforded a 73:27 mixture of the diastereomeric phosphine oxides $7 \mathbf{a} / 7$ 'a (86\%). The major diastereomer 7a corresponds to a sigmatropic rearrangement occurring on the most hindered face (cis to the aromatic group) of the cyclopropene which was somewhat surprising. Substitution at the para-position of the aromatic group at C3 significantly affected the diasteomeric ratio with an increase observed with the mesomeric donor methoxy group in favor of diastereomer $\mathbf{7 b}$ $\left(\mathbf{7 b} / \mathbf{7}^{\prime} \mathbf{b}=78: 22\right)$ compared to $\mathbf{7 a / 7} \mathbf{a}$, and a drop of diastereoselectivity when a fluorine atom $\left(\mathbf{7} \mathbf{c} / \mathbf{7}^{\prime} \mathbf{c}=60: 40\right)$ or a hydrogen atom $\left(\mathbf{7} \mathbf{d} / \mathbf{7}^{\prime} \mathbf{d}=52: 48\right)$ were present. An inversion of the face selectivity was detected in favor of diastereomer 7 'e $(\mathbf{7} \mathbf{e} / \mathbf{7} \mathbf{e}=43: 57)$ arising from the rearrangement of phosphinite 6e possessing a $p$-trifluoromethylphenyl substituent. Replacement of the acetal protecting group of the hydroxymethyl substituent at $\mathrm{C} 3\left(\mathrm{R}^{3}=\mathrm{CH}_{2} \mathrm{OMOM}=\mathrm{CH}_{2} \mathrm{OCH}_{2} \mathrm{OMe}\right)$ by an acetate $\left(\mathrm{R}^{3}=\mathrm{CH}_{2} \mathrm{OAc}\right)$ did not affect the results, as illustrated in the case of $\mathbf{7 f} / \mathbf{7}^{\prime} \mathbf{f}$, but the presence of an ester moiety $\left(\mathrm{R}^{3}=\mathrm{CO}_{2} \mathrm{Me}\right)$ led to the rearranged phosphine oxides $7 \mathbf{g} / \mathbf{7}^{\prime} \mathbf{g}$ in rather low yield (47\%) although the diasteromeric ratio remains 
similar to that observed for $\mathbf{7 a} / \mathbf{7}$ 'a. Other substituents were tolerated on the phosphorus atom including an isopropyl or a cyclohexyl group and the corresponding phosphine oxides $\mathbf{7 h} / \mathbf{7}^{\prime} \mathbf{h}$ and $\mathbf{7} \mathbf{i} / \mathbf{7}^{\prime} \mathbf{i}$ were isolated in good yields. Increasing the steric hindrance around the phosphorus atom resulted in a higher diastereoselectivity. However, the sigmatropic rearrangement of the highly hindered di(tert-butyl)phosphinite $\mathbf{6 j}$ and tetra(isopropyl) phosphorodiamidite $\mathbf{6 k}$ did not occur (Scheme 7) [37].

The mechanism proposed by Rubin et al. involves a reversible addition of the Lewis base (DBU) on the cyclopropene double bond at $\mathrm{C} 2$ leading to zwitterronic intermediates $\mathbf{8}$ and $\mathbf{8}^{\text {'. This }}$ would result in an increase of conformational flexibility thereby facilitating the nucleophilic displacement of the ammonium by the phosphinite through transition states TS1 and TS2 $\left(\mathrm{S}_{\mathrm{N}} 2-\right.$ type process), respectively. Oxaphospholanium zwitterions 9 and 9' would then be obtained and would eventually produce the diastereomeric phosphine oxides 7 and 7'. Computational studies indicated that the facial selectivity of the initial attack of the Lewis base (DBU) was not responsible for the observed diastereocontrol because of the low difference between the activation barriers of the reactions leading to $\mathbf{8}$ and $\mathbf{8}$ ', regardless of the aromatic substituent. Since $\mathbf{8}$ and $\mathbf{8}$ ' were in rapid equilibrium with phosphinite $\mathbf{6}$, the diastereoselectivity should depend on the relative stabilities of the transition states TS1 and TS'1. An electron-donating group at the para-position of the aromatic ring could contribute to the stabilization of TS1, in which the $\mathrm{Ar}-\mathrm{C} 3-\mathrm{C} 2-\mathrm{P}$ dihedral angle is close to $0^{\circ}$, by considering the mesomeric form TS2. The observed dependence of the diastereoselectivity on the $\sigma^{+}$Hammett constant of the para substituents further supported the proposed mechanism (Scheme 8) [37].

To date and to the best of our knowledge, reports on [2,3]sigmatropic rearrangements of cyclopropenylcarbinol derivatives appear to be limited to the synthesis of alkylidenecyclopropanes incorporating a phosphorus atom. Cyclopropenylcarbinol derivatives can also lead to other heterosubstituted alkylidenecyclopropanes by using [3,3]-sigmatropic rearrangements.

\section{[3,3]-Sigmatropic rearrangements involving cyclopropenylcarbinol derivatives \\ Access to heterosubstituted alkylidenecyclopropanes}

The interest of secondary cyclopropenylcarbinol derivatives in $[3,3]$-sigmatropic rearrangements was first highlighted by Marek et al. who investigated the transposition of cyclopropenylcarbinyl esters $[33,34]$. The [3,3]-sigmatropic rearrangement of acetate 10a took place during filtration on silica gel and afforded alkylidene(acetoxycyclopropane) 11a in $90 \%$ yield. The ease with which the rearrangement of $\mathbf{1 0 a}$ occurred was attributed to the relief of ring strain but also to the favorable conjugation of the olefin with the two phenyl groups $\left(\mathrm{R}^{1}=\mathrm{R}^{1}=\mathrm{Ph}\right)$. Alkylidenecyclopropane 11a could also be obtained in similar yields ( $92 \%$ or $87 \%$, respectively) by heating acetate $10 \mathrm{a}$ in dichloromethane at reflux or by treatment with

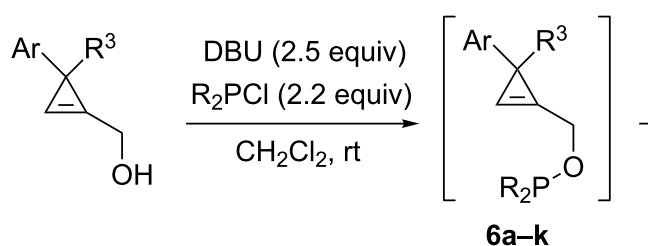

$40^{\circ} \mathrm{C}, 10-20 \mathrm{~h}$

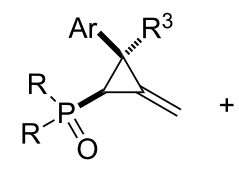

7a-k

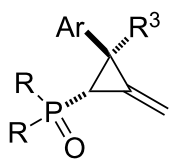

7'a-'k

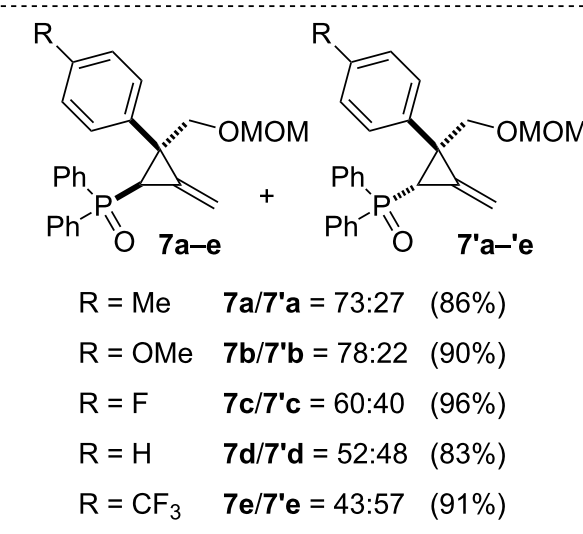

$\mathrm{Me}$

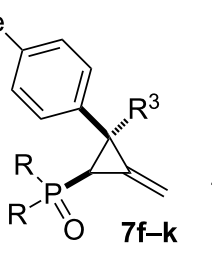

$\mathrm{Me}$

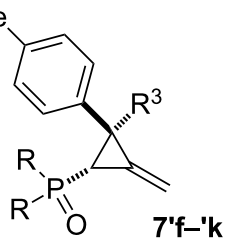

$$
\begin{array}{ll}
\mathrm{R}=\mathrm{Ph}, \mathrm{R}^{3}=\mathrm{CH}_{2} \mathrm{OAc} & \mathbf{7 f} / \mathbf{7}^{\prime} \mathbf{f}=74: 26 \\
\mathrm{R}=\mathrm{Ph}, \mathrm{R}^{3}=\mathrm{CO}_{2} \mathrm{Me} & \mathbf{7 g} / \mathbf{7}^{\prime} \mathbf{g}=71: 29 \\
\mathrm{R}=\mathrm{iPr}, \mathrm{R}^{3}=\mathrm{CH}_{2} \mathrm{MOM} & \mathbf{7 h} / \mathbf{7}^{\prime} \mathbf{h}=80: 20 \\
\mathrm{R}=\mathrm{Cy}, \mathrm{R}^{3}=\mathrm{CH}_{2} \mathrm{OMOM} & \mathbf{7 i} / \mathbf{7}^{\prime} \mathbf{i}=84: 16 \\
\mathrm{R}=t-\mathrm{Bu}, \mathrm{R}^{3}=\mathrm{CH}_{2} \mathrm{OMOM} & \mathbf{7} \mathbf{j} / \mathbf{7}^{\prime} \mathbf{j} \\
\mathrm{R}=\mathrm{NiPr}_{2}, \mathrm{R}^{3}=\mathrm{CH}_{2} \mathrm{OMOM} & \mathbf{7 k} / \mathbf{7}^{\prime} \mathbf{k}
\end{array}
$$




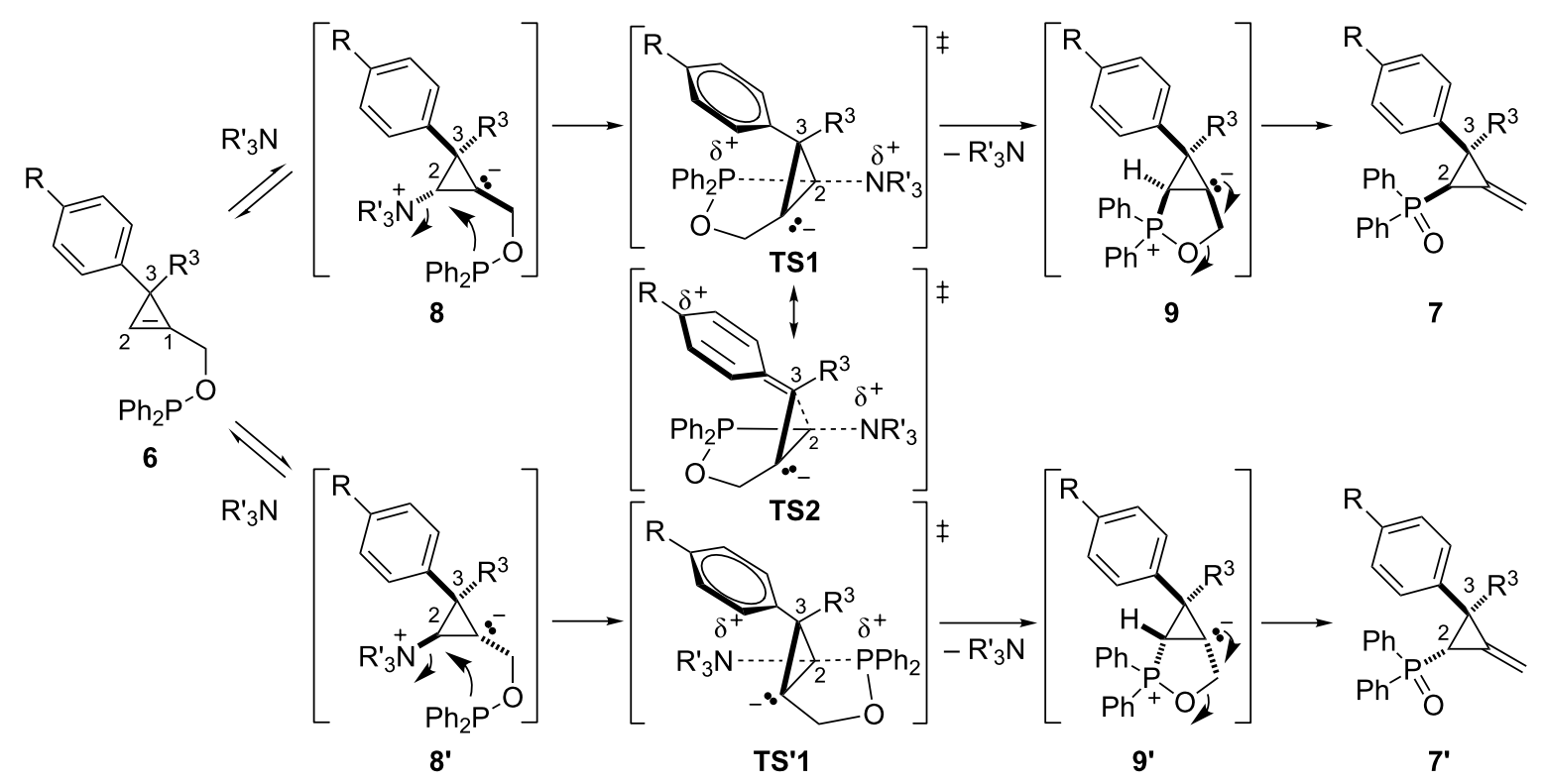

Scheme 8: Proposed mechanism for the Lewis base-catalyzed rearrangement of phosphinites 6.

dry Amberlyst ${ }^{\circledR} 15$ (a sulfonic acid resin) [33,34]. The rearrangement of the tertiary acetates $10 b\left(R^{1}=R^{1}=\mathrm{Me}\right)$ and $\mathbf{1 0 c}$ $\left(\mathrm{R}^{1}=\mathrm{Ph}, \mathrm{R}^{1}=\mathrm{Me}\right)$ could also be achieved by filtration through silica gel and led to $\mathbf{1 1 b}(91 \%)$ and $11 \mathbf{c}(83 \%)$. The latter non-symmetrical tetrasubstituted alkene 11c was obtained as a 67:33 mixture of geometric isomers (Scheme 9) [33,34].
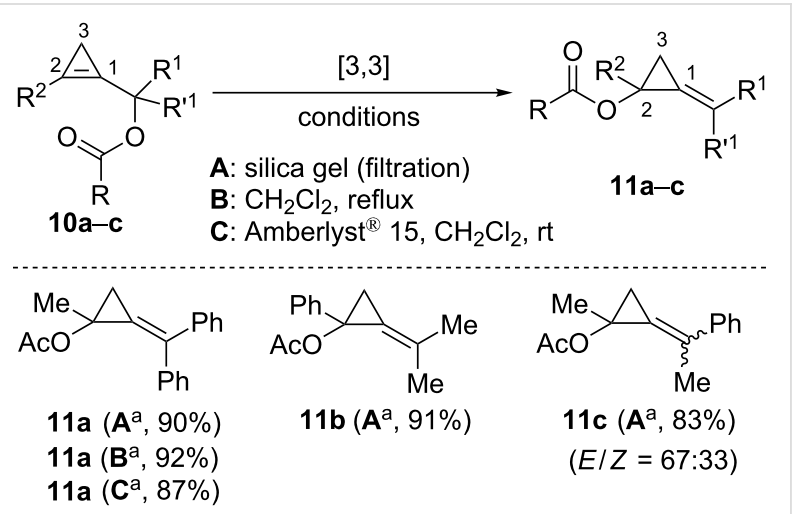

${ }^{\text {aconditions used. }}$

Scheme 9: [3,3]-Sigmatropic rearrangement of tertiary cyclopropenylcarbinyl acetates $10 a-c$.

The rearrangement of secondary cyclopropenylcarbinyl acetates 10d-g could be achieved in the presence of Amberlyst ${ }^{\circledR} 15$ and led exclusively to the $(E)$-alkylidene(acetoxycyclopropanes) 11d-g $(E / Z>99: 1)$ in good yields $(70-77 \%)$. The acetate could also be replaced by a benzoate as illustrated with the formation of alkylidenecyclopropane $11 \mathrm{~h}(60 \%)$ from substrate $10 \mathrm{~h}$. The authors mentioned that the sigmatropic rearrangement did not proceed under such mild conditions for substrates possessing an alkyl group instead of an aryl group at $\mathrm{C} 4$ but no additional details were provided. The high diastereoselectivity was explained by considering a six-membered chair-like cyclic transition state model TS3 in which the substituent at the $\alpha$ position of the ester (C4) preferentially occupies a pseudo-equatorial position. Although a cationic mechanism could have also been envisioned under the acidic conditions used, the optically enriched acetates $10 \mathrm{~d}$ and $\mathbf{1 0 e}$ (ee $>98 \%$ ) led to the corresponding alkylidenecyclopropanes $\mathbf{1 1 d}$ and $11 \mathrm{e}$ with complete chirality transfer (ee $>98 \%$ ) at $\mathrm{C} 2$, thereby probing the concerted suprafacial nature of the rearrangement (Scheme 10) $[33,34]$. The acidic promotor may be simply assisting the dissociation of the C4-O bond in the transition state TS3 whilst an aromatic group $\left(\mathrm{R}^{1}=\mathrm{Ar}\right)$ would contribute to the stabilization of a developing positive charge at $\mathrm{C} 4$.

The [3,3]-sigmatropic rearrangement of cyclopropenylcarbinyl acetates provides a straightforward and stereoselective entry to alkylidene(acyloxycyclopropanes). Only a few compounds of this family had been previously generated by photochemical reactions (from 4-isopropylidene-3,3-dimethyl-1-thietan-2thione [38] or from a 4-alkylidene- $\Delta^{1}$-pyrazoline [39]) or by pyrolysis of the sodium salt of 3-propionyloxytetramethylcyclobutanone tosyl hydrazone [40]. It is also worth mentioning that completely divergent reactivities have also been reported for cyclopropenylcarbinyl esters in the presence of transition metal catalysts $[41,42]$. 


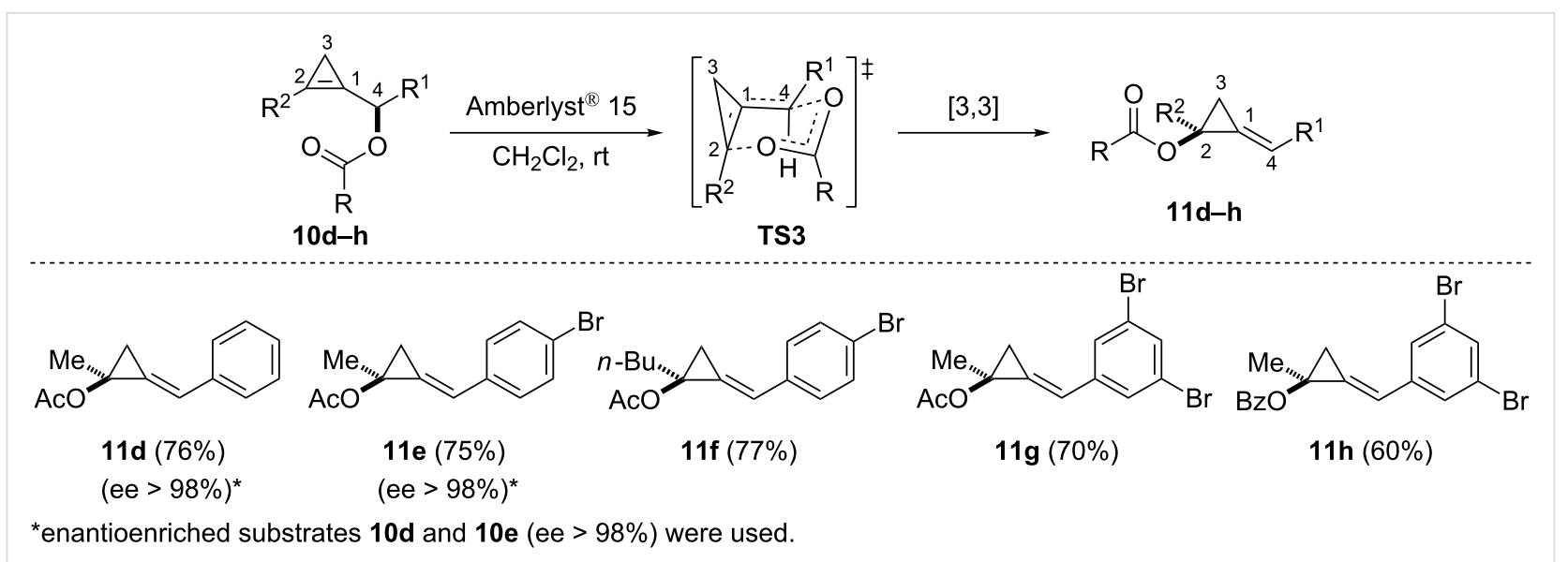

Scheme 10: [3,3]-Sigmatropic rearrangement of secondary cyclopropenylcarbinyl esters $\mathbf{1 0 d}-\mathbf{h}$.

Alkylidene(aminocyclopropane) derivatives constitute another interesting class of heterosubstituted alkylidenecyclopropanes which have been previously synthesized by a Curtius rearrangement of acyl azides derived from alkylidenecyclopropane carboxylic acids [43] or by elimination reactions applied to suitably substituted aminocyclopropane derivatives [44-46].

In 2014, Hyland et al. disclosed the Overman rearrangement [47] of cyclopropenylcarbinyl trichloroacetimidates [48]. The optimal conditions for the generation of imidates 12a-i involved treatment of secondary cyclopropenylcarbinols with trichloroacetonitrile in the presence of a catalytic amount of DBU (15 mol \%) in $\mathrm{CH}_{2} \mathrm{Cl}_{2}\left(-78{ }^{\circ} \mathrm{C}\right.$ to $\left.-10{ }^{\circ} \mathrm{C}, 2-3 \mathrm{~h}\right)[48,49]$. The crude imidates $12 \mathbf{a}-\mathbf{i}$ were then directly engaged in the $[3,3]$-sigmatropic rearrangement step which was triggered by heating in the presence of $\mathrm{K}_{2} \mathrm{CO}_{3}$ in $\mathrm{CH}_{2} \mathrm{Cl}_{2}\left(30{ }^{\circ} \mathrm{C}, 40 \mathrm{~h}\right)$.
These latter conditions, which were optimized for imidate 12a, enabled the formation of $p$-bromobenzylidene[ $(N$-trichloroacetylamino)cyclopropane] 13a as a single $(E)$-isomer in $63 \%$ overall yield (two steps from the corresponding alcohol). Compound 13a was obtained in lower yield in the absence of a base $(21 \%)$ or when DMF was used as the solvent (53\%) though a considerable rate acceleration ( $22 \mathrm{~h}$ instead of $40 \mathrm{~h}$ ) was observed compared to $\mathrm{CH}_{2} \mathrm{Cl}_{2}$. In the presence of $\mathrm{PdCl}_{2}\left(\mathrm{MeCN}_{2}(5 \mathrm{~mol} \%)\right.$, only traces of 13a were detected and significant decomposition of 12a took place. As in the case of the [3,3]-sigmatropic rearrangement of cyclopropenylcarbinyl acetates, the observed stereoselectivity was explained by invoking a chair-like transition state model TS4 in which the aryl group preferentially occupies a pseudo-equatorial orientation (Scheme 11) [48]. Although the presence of a halogen atom was tolerated, as illustrated with the formation of the benzyli-

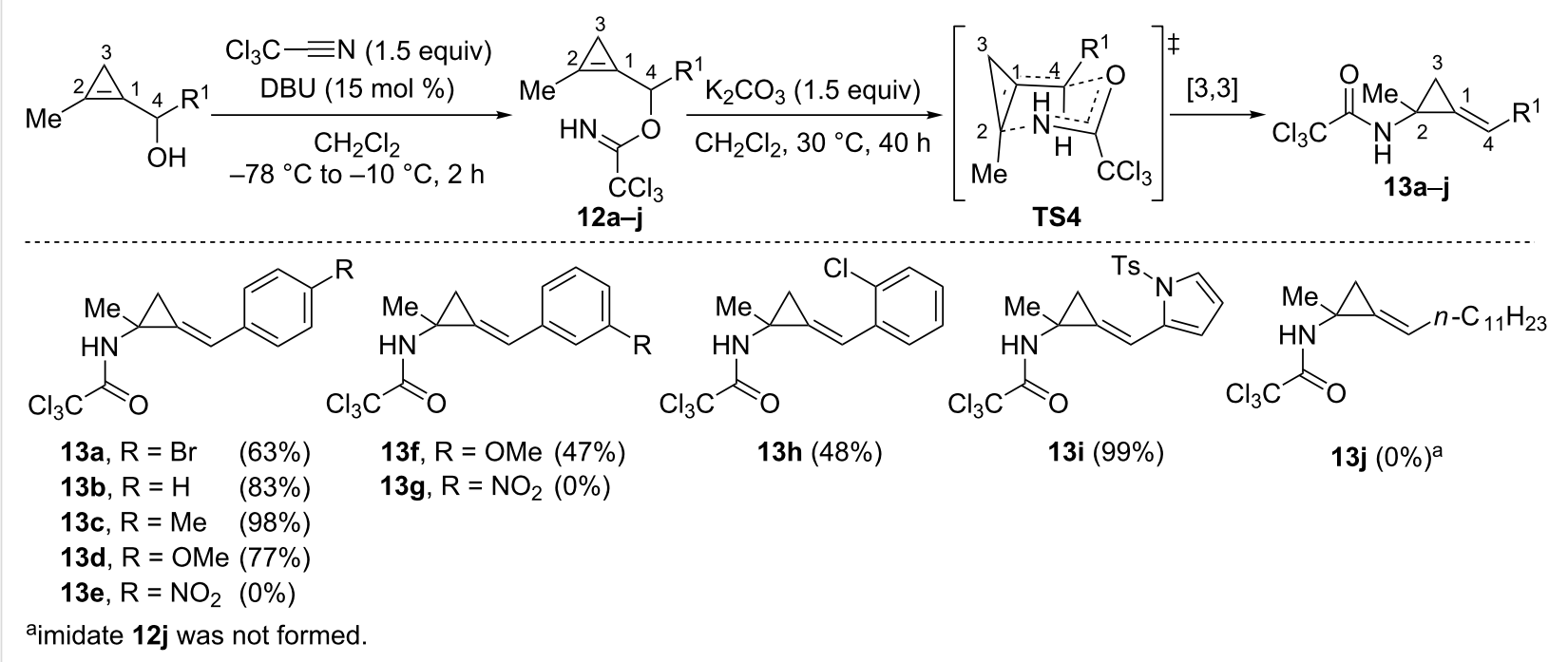


denecyclopropanes 13a (63\%) and 13h (48\%), higher yields were obtained in the case of imidates $\mathbf{1 3 b} \mathbf{b}-\mathbf{d}$, possessing an electro-neutral or an electron-rich aromatic group, which afforded compounds 13b (83\%), 13c (98\%) and 13d (77\%), substituted by a phenyl, a $p$-tolyl or a $p$-anisyl group, respectively. The rearrangement of imidate $\mathbf{1 2 f}$ possessing a $m$-anisyl substituent afforded benzylidene cyclopropane $\mathbf{1 3 f}$ in a lower yield (47\%) compared to $\mathbf{1 3 d}(77 \%)$. The rearrangement of imidate $\mathbf{1 2 i}$ possessing an electron-rich $N$-tosylpyrrol-2-yl heteroaromatic group, afforded alkylidenecyclopropane 13i in nearly quantitative yield. Conversely, no rearrangement took place in the case of imidates $\mathbf{1 2 \mathrm { e }}$ and $\mathbf{1 2 \mathrm { g }}$ in which the aromatic group was substituted by a strongly electron-withdrawing nitro group at the para- or the meta-position, respectively. All these observations point toward the development of a positive charge at the $\mathrm{C} 4$ carbon atom (adjacent to the $\mathrm{R}^{1}$ substituent) in the transition state TS4, as was also suggested previously in the [3,3]-sigmatropic rearrangement of cyclopropenylcarbinyl acetates. Alkylidenecyclopropane $\mathbf{1 3} \mathbf{j}$ could not be synthesized because trichloroacetimidate $\mathbf{1 2} \mathbf{j}$ was not obtained by treatment of the corresponding cyclopropenylcarbinol substituted by an $n$-undecyl group with trichloroacetonitrile, even under forcing conditions. The authors tentatively suggested this may be due to the sterically hindered $n$-undecyl chain although this issue was not fully investigated (Scheme 11) [48].

While attempts to access the free alkylidene(aminocyclopropanes) from the corresponding trichloroacetamides proved unsuccessful by hydrolysis (1 $\mathrm{M}$ aqueous $\mathrm{HCl}$ or $\mathrm{KOH}, \mathrm{EtOH}$ ) or reduction (DIBAL-H or $\mathrm{NaBH}_{4}$ ), Hyland et al. showed that the treatment of (arylmethylene)cyclopropane 13f with $\mathrm{Cs}_{2} \mathrm{CO}_{3}$ in anhydrous DMF, followed by the addition of an excess of pyrrolidine, produced urea $14 \mathbf{f}(24 \%)$ [ 48,49$]$. The moderate yield of $\mathbf{1 4 f}$ was attributed to the instability of the in situ-generated isocyanate $\mathbf{1 5 f}$ under the reaction conditions [50]. When trichloroacetamide 13f was treated with an excess of pyrrolidine and $\mathrm{Cs}_{2} \mathrm{CO}_{3}$ in bench grade (undried) DMF, the reaction followed a different pathway and delivered $\alpha$-oxoacetamide $\mathbf{1 6 f}$ $(58 \%)$ instead of urea $\mathbf{1 4 f}[48,49]$. This type of transformation had already been reported [51] and interpreted by a Favorskiitype mechanism, presumably involving the formation of the gem-dichloro- $\alpha$-lactam intermediate $\mathbf{1 7 f}$ which would undergo ring opening by nucleophilic addition of pyrrolidine followed by hydrolysis of the resulting $\alpha, \alpha$-dichloro- $\alpha$-aminoacetamide $18 f$ (Scheme 12).

To access aminocyclopropanes, the hydrogenation of (arylmethylene)cyclopropane 13f was achieved in the presence of $\mathrm{Pd} / \mathrm{C}$ as a catalyst. Concomitant hydrogenolysis of two carbon-chlorine bonds also took place under these conditions and a 71:29 diastereomeric mixture of the monochloracetamides 19f/19' $\mathbf{f}$ was obtained (41\%). The rather small difference of steric hindrance between the methyl and the $N$-acylamino group explained the modest face selectivity of hydrogen addition which preferentially occurred on the face of the olefin opposite to the $N$-chloroacetylamino substituent (Scheme 13) [48].

3,3-Disubstituted cyclopropenylcarbinols could not be used as substrates in the Overman rearrangement. This limitation of the substrate scope is due to the instability of the corresponding trichloroacetimidates. Thus cyclopropenylcarbinols $\mathbf{2 0 a}-\mathbf{c}$ possessing gem-dimethyl substitution at $\mathrm{C} 3$ were converted to imidates 21 a-c but upon treatment with silica gel $\left(\mathrm{CH}_{2} \mathrm{Cl}_{2}\right.$, $-10{ }^{\circ} \mathrm{C}$ ), those latter compounds were converted into $\alpha$-allenic tertiary alcohols 22a-c (30-61\%) The formation of alcohols 22a-c was explained by a mechanism involving ionization of

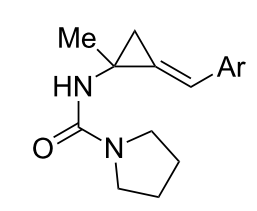

14f, $\mathrm{Ar}=m-\mathrm{OMe}-\mathrm{C}_{6} \mathrm{H}_{4}$<smiles>CC1CCCN1</smiles>

1) $\mathrm{Cs}_{2} \mathrm{CO}_{3}$ (2.5 equiv)

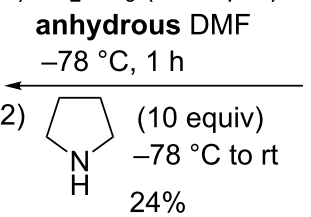<smiles>CC1(NC(=O)C(Cl)(Cl)Cl)C/C1=C\[Al]</smiles>

13f, $\mathrm{Ar}=m-\mathrm{OMe}-\mathrm{C}_{6} \mathrm{H}_{4}$<smiles>C[Al]/C=C1\CC1(C)N=C=O</smiles>

$\left\langle\mathrm{H}_{\mathrm{H}}\right.$ (10 equiv)

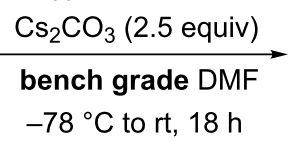

$58 \%$<smiles>CC1(N2C(=O)C2(Cl)CC2CC2)CC1(Cl)Cl</smiles><smiles>CC1(NC(=O)C(=O)N2CCCC2)C/C1=C\[Al]</smiles>

16f, $\mathrm{Ar}=m-\mathrm{OMe}-\mathrm{C}_{6} \mathrm{H}_{4}$

$\uparrow \mathrm{H}_{2} \mathrm{O}$

$15 f$ 

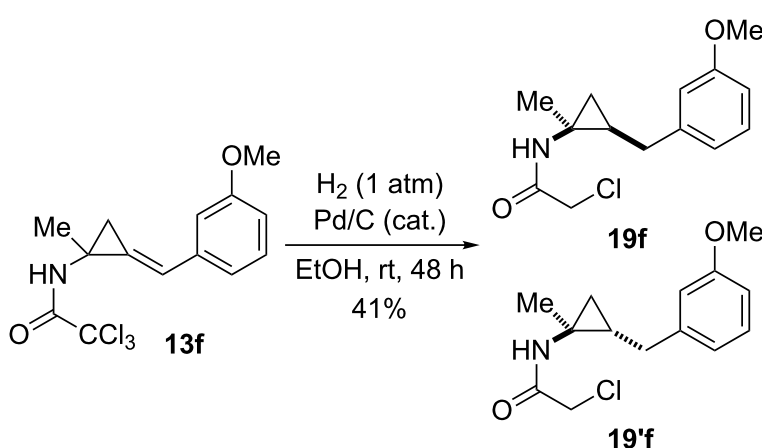

$(19 f / 19 ' f=71: 29)$

Scheme 13: Catalytic hydrogenation of (arylmethylene)cyclopropropane 13f.

the $\mathrm{C} 4-\mathrm{O}$ bond in imidates $21 \mathbf{a}-\mathbf{c}$, followed by ring opening of the alkylidenecyclopropyl cationic intermediates 23a-c [52] and addition of water to the resulting $\alpha$-allenic carbocations $\mathbf{2 4 a - c}$ (Scheme 14) [48].

$$
\overbrace{2}^{\mathrm{Me}} \mathrm{Me}
$$

20a, $\mathrm{Ar}=\mathrm{Ph}$

20b, $\mathrm{Ar}=p-\mathrm{Br}-\mathrm{C}_{6} \mathrm{H}_{4}$

20c, $\mathrm{Ar}=\mathrm{O}-\mathrm{F}-\mathrm{C}_{6} \mathrm{H}_{4}$

$$
\underset{\substack{\mathrm{CBU}(15 \mathrm{~mol} \%) \\-78^{\circ} \mathrm{C} \text { to }-10^{\circ} \mathrm{C}, 2 \mathrm{~h}}}{\mathrm{CH}_{2} \mathrm{Cl}_{2}}
$$

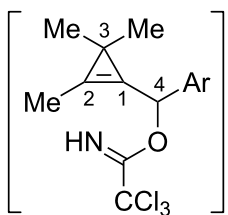

21a-c

$$
\mathrm{CH}_{2} \mathrm{Cl}_{2},-10{ }^{\circ} \mathrm{C} \text { to } \mathrm{rt}
$$

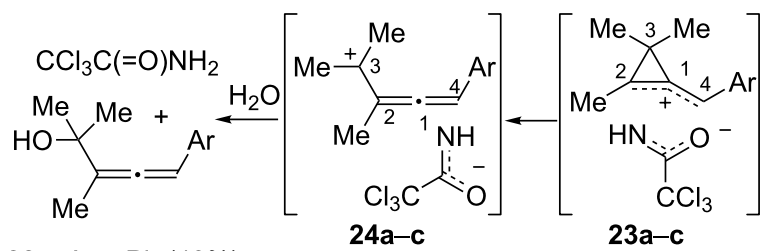

22a, $\mathrm{Ar}=\mathrm{Ph}(48 \%)$

22b, $\mathrm{Ar}=p-\mathrm{Br}_{-} \mathrm{C}_{6} \mathrm{H}_{4}(61 \%)$

22c, $\mathrm{Ar}=0-\mathrm{F}-\mathrm{C}_{6} \mathrm{H}_{4}(30 \%)$

Scheme 14: Instability of trichloroacetimidates 21a-c derived from cyclopropenylcarbinols $20 \mathrm{a}-\mathrm{c}$.

As a complementary strategy, our group examined the [3,3]sigmatropic rearrangement of cyanates derived from cyclopropenylcarbinols [53]. The allyl cyanate to isocyanate rearrangement displays many interesting features such as the possibility to generate the reactive species by dehydration of carbamates under mild conditions and the ultimate formation of isocyanates which can be derivatized in situ [54]. The conditions were optimized with alcohol $\mathbf{2 5}$ substituted by a 2-phenylethyl group at the oxygen-bearing carbon atom (C4) and possessing gem-disubstitution at $\mathrm{C} 3$ on the three-membered ring. Alcohol 25 was readily converted to carbamate 26 by reac- tion with trichloroacetyl isocyanate followed by cleavage of the trichloroacetyl group by alkaline hydrolysis. Dehydration of carbamate $\mathbf{2 6}$ was achieved by treatment with trifluoroacetic anhydride in the presence of triethylamine under mild conditions $\left(\mathrm{CH}_{2} \mathrm{Cl}_{2},-78{ }^{\circ} \mathrm{C}\right)[55]$ and the in situ-generated cyanate 27 underwent a sigmatropic rearrangement into the corresponding isocyanate 28. The formation of this reactive isocyanate intermediate was ascertained by the addition of morpholine which enabled the isolation of urea 29 in good yield (78\%). It is worth noting that alkylidenecyclopropane $\mathbf{2 9}$ was formed with high diastereoselectivity $(E / Z \geq 95: 5)$ at low temperature $\left(-78^{\circ} \mathrm{C}\right)$ but a slight erosion of diastereoselectivity was observed $(E / Z=88: 12)$ when the same sequence was performed at $0{ }^{\circ} \mathrm{C}$. The stereochemical outcome was in agreement with a six-membered transition state model TS5 in which the three atoms of the cyanate $(\mathrm{O}=\mathrm{C}=\mathrm{N})$ moiety would be arranged in an almost linear fashion (an angle of $173^{\circ}$ was calculated in the allyl cyanate to isocyanate transition state) [56] and the substituent at $\mathrm{C} 4$ would preferentially occupy a pseudo-equatorial orientation. Additionally, the same sequence applied to the enantioenriched alcohol $(R)-\mathbf{2 5}(\mathrm{ee}=88 \%)$ delivered urea $(-)-29$ with essentially the same optical purity $(\mathrm{ee}=86 \%$ ), thereby indicating that chirality transfer (from $\mathrm{C} 4$ to $\mathrm{C} 2$ ) occurred during the sigmatropic rearrangement of cyanate $\mathbf{2 7}$ into isocyanate $\mathbf{2 8}$ (Scheme 15) [53].

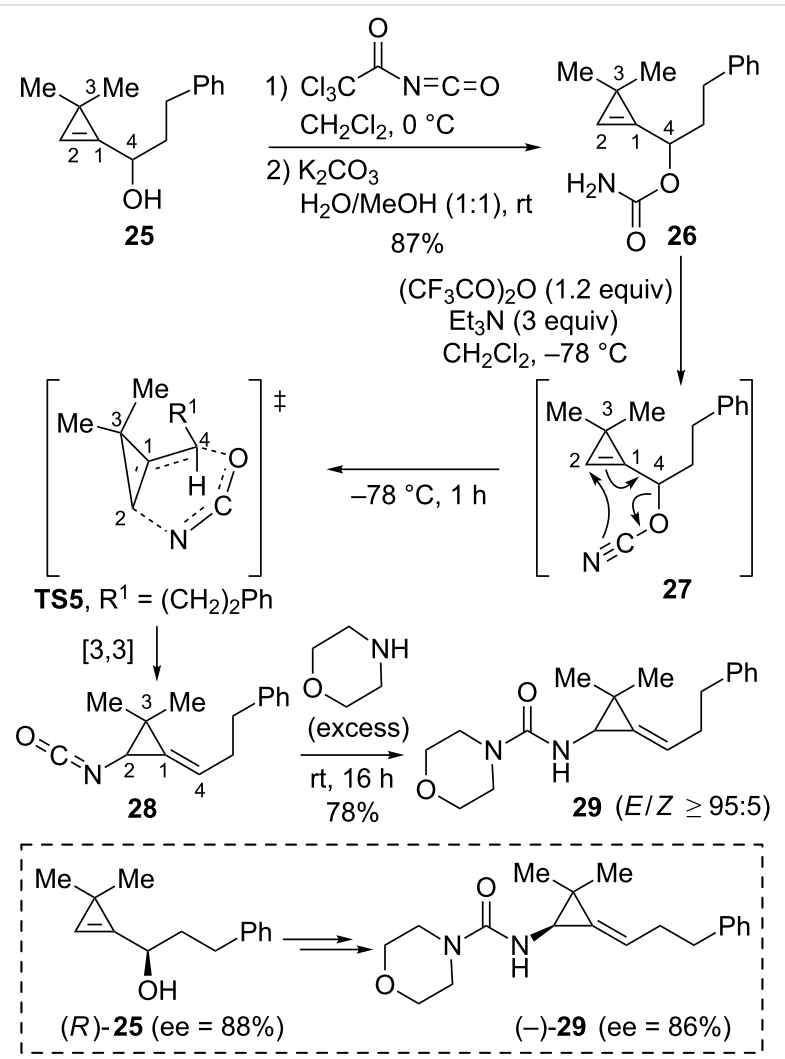

Scheme 15: [3,3]-Sigmatropic rearrangement of cyanate 27 generated from cyclopropenylcarbinyl carbamate $\mathbf{2 6}$. 
All attempts to isolate isocyanate $\mathbf{2 8}$ were unsuccessful but derivatization of this latter reactive intermediate could be achieved in situ by addition of a broad range of nucleophiles, which were either used as co-solvents or added in excess. Thus, reaction with pyrrolidine, imidazole, methanol, allyl alcohol, benzyl alcohol and 9-fluorenemethanol $(\mathrm{FmOH})$ provided the corresponding urea 30, $\mathrm{N}$-carbamoyl imidazole 31 and carbamates 32-35, respectively, in good yields (69-80\%). The reaction of isocyanate $\mathbf{2 8}$ with tert-butanol was sluggish even by heating at $40{ }^{\circ} \mathrm{C}$ but could be accelerated by addition of $\mathrm{Ti}(\mathrm{OiPr})_{4}(10 \mathrm{~mol} \%)$ to deliver the corresponding $N$-Boccarbamate $36(81 \%)$. The condensation of isocyanate 28 with $N$-Boc-glycine in the presence of DMAP (Goldschmidt-Wick coupling) [57] provided amide 37 in 70\% yield (Scheme 16) [53].

The examination of the substrate scope indicated that a broad range of alkyl chains, possibly incorporating heteroatoms, were compatible with the dehydration-[3,3]-sigmatropic sequence, as illustrated with the isolation of compounds 38-40 (72-79\%) after nucleophilic trapping of the generated isocyanate intermediates with allyl alcohol. Benzylidenecyclopropane 41 was also obtained in good yield (70\%) but the efficiency of the sigmatropic rearrangement dropped for carbamates in which the aromatic group at $\mathrm{C} 4$ is substituted by an electron-withdrawing group at the para-position. Indeed, $N$-Alloc (arylmethylene)(aminocyclopropanes) 42 and $\mathbf{4 3}$, substituted by a $p$-fluorophenyl and a $p$-(trifluoromethyl)phenyl group, respectively, were isolated in moderate yield (53\%). Moreover, ( $p$-nitrophenylmethylene)cyclopropane $\mathbf{4 4}$ could not be obtained under these conditions [53]. These results indicate that the [3,3]sigmatropic rearrangement of cyclopropenylcarbinyl cyanates, as previously reported for their allylic counterparts [56], does not involve a synchronous process because dissociation of the $\mathrm{C} 4-\mathrm{O}$ bond is more advanced in the transition state TS5 than the formation of the $\mathrm{C} 2-\mathrm{N}$ bond (Scheme 15). The rearrangement of cyclopropenylcarbinyl cyanates accommodates various substituents at C3, as well as the presence of a substituent at $\mathrm{C} 2$ or even a fully substituted cyclopropene ring, as shown with the successful formation of alkylidenecyclopropanes 45-48 (58-86\%, Scheme 17) [53].

Interestingly, alkylidene(isocyanatocyclopropanes) arising from the [3,3]-sigmatropic rearrangement of cyclopropenylcarbinyl cyanates could also be derivatized into trifluoroacetamides. This transformation was discovered fortuitously when carbamate 49 was treated with an excess of trifluoroacetic anhydride ( 2 equiv) in the presence of $\mathrm{Et}_{3} \mathrm{~N}$ ( 3 equiv) to achieve the dehydration-sigmatropic rearrangement sequence. Trifluoroacetamide $50(67 \%)$ was the product directly formed under these conditions and the Lewis basic character of the pyridine ring was suspected to be responsible for the observed reactivity (Scheme 18).

With the aim of achieving the same derivatization in the case of other substrates devoid of a pyridine ring, several 3,3-dimethylcyclopropenylcarbinyl carbamates were engaged in the dehydration-[3,3]-sigmatropic rearrangement sequence under the previously used conditions but trifluoroacetic anhydride (1.5 equiv) and pyridine (1.5 equiv) were then subsequently added to the reaction mixture. Under these conditions, the corresponding trifluoroacetamides 51-54 could be effectively isolated in good yields (73-85\%). The addition of pyridine to the isocyanates $\mathbf{J}$ arising from the [3,3]-sigmatropic rearrangement would probably generate the zwitterionic intermediates $\mathbf{K}$ which would then react with trifluoroacetic anhydride to

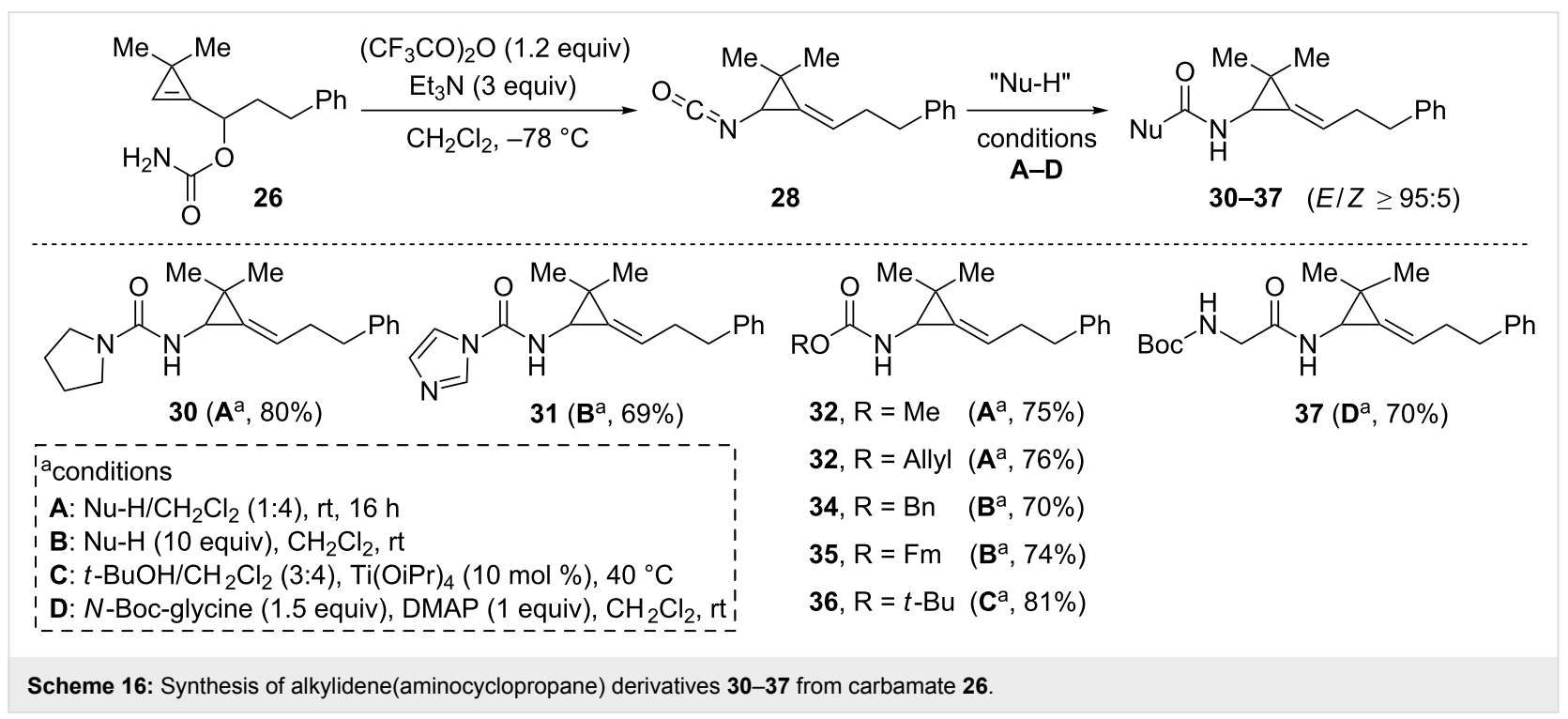




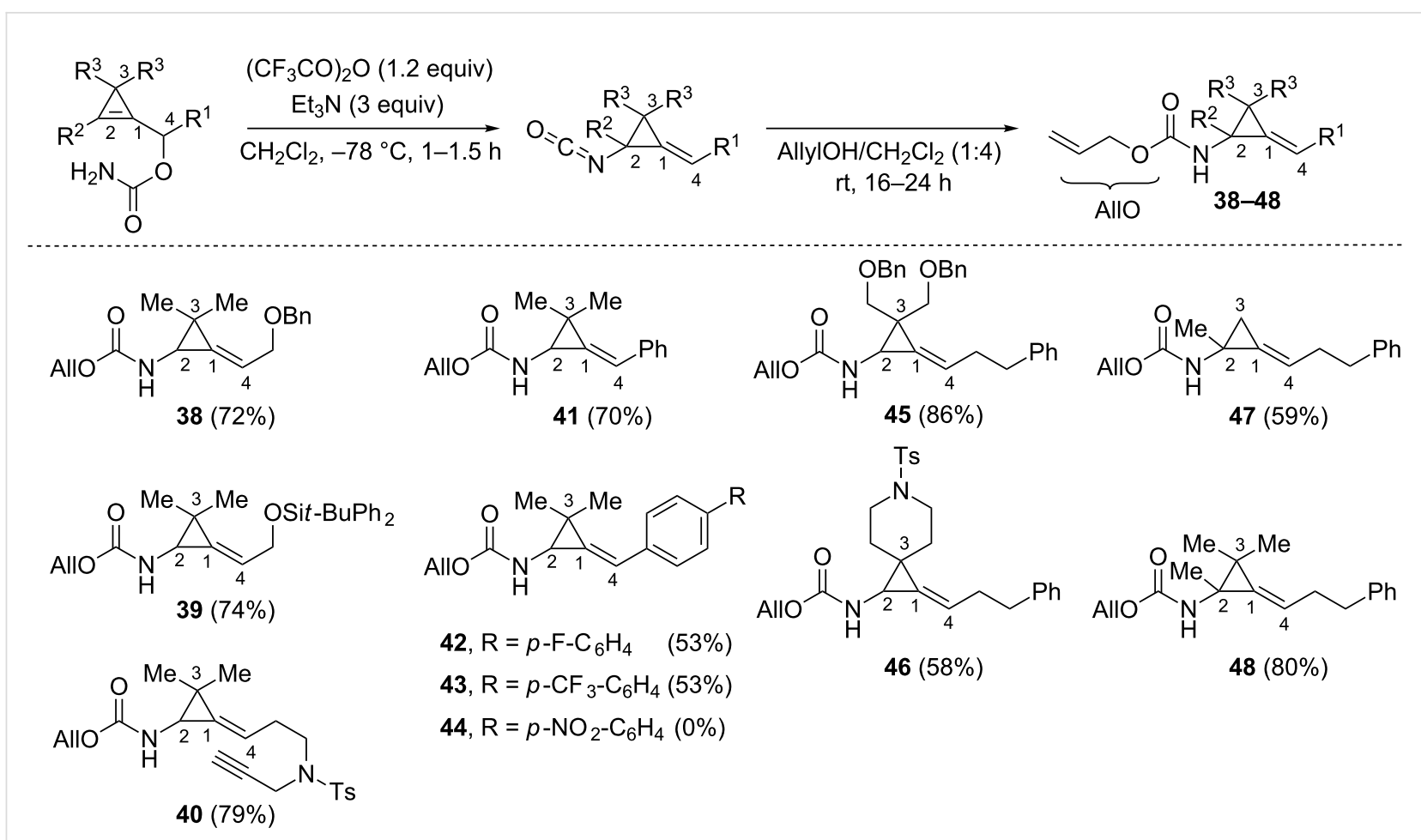

Scheme 17: Scope of the dehydration-[3,3]-sigmatropic rearrangement sequence of cyclopropenylcarbinyl carbamates.

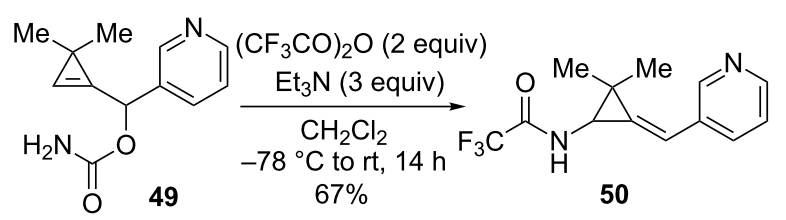

Scheme 18: Formation of trifluoroacetamide $\mathbf{5 0}$ from carbamate 49.

produce $\mathrm{N}, \mathrm{O}$-bis(trifluoroacetyl)carbamates $\mathbf{L}$. Trifluoroacetamides 51-54 would be generated from adducts $\mathbf{L}$ after hydrolysis of the reaction mixture (Scheme 19) [53].

To control the diastereoselectivity of the hydrogenation of alkylidene[( $N$-acylamino $)$ cyclopropanes] possessing a single substituent at $\mathrm{C} 2$, it is possible to rely either on the steric hindrance or on the coordinating ability of the amide group. Thus, the hydrogenation of trifluoroacetamide $\mathbf{5 1}$ catalyzed by $\mathrm{Pd} / \mathrm{C}$ afforded $\mathrm{N}$-trifluoroacetylaminocyclopropane $\mathbf{5 5}$ as the major diastereomer $\left(\mathbf{5 5} / \mathbf{5 5}^{\prime}=92: 8\right)$ because of the preferential addition of hydrogen on the less hindered face of the trisubstituted alkene opposite to the trifluoroacetamide moiety. A reversal of face selectivity can be observed by performing a directed iridium(I)-catalyzed hydrogenation in the presence of Crabtree's catalyst [58] which afforded aminocyclopropane 55' as the major diastereomer $(\mathbf{5 5}, \mathbf{5 5}=90: 10$, Scheme 20) [53].
The potential of $[3,3]$-sigmatropic rearrangements involving cyclopropenylcarbinol derivatives is not restricted to the synthesis of heterosubstituted alkylidenecyclopropanes and was also exploited to access functionalized alkylidenecyclopropanes, with creation of a new carbon-carbon bond on the three-membered ring with the control of two contiguous stereocenters.

\section{Ireland-Claisen rearrangement of cyclopropenyl- carbinyl esters}

The Ireland-Claisen rearrangement of silyl ketene acetals generated from allylic (or propargylic) esters is arguably one of the most useful variant of the Claisen rearrangement that has found countless applications in organic synthesis [59]. The feasibility of the Ireland-Claisen rearrangement of cyclopropenylcarbinyl esters was investigated in the case of glycolates 56a-l which were readily prepared by coupling of the corresponding cyclopropenylcarbinols with (4-methoxybenzyloxy)acetic acid. Enolization of glycolates 56a-1 was carried out by treatment with $\mathrm{Me}_{3} \mathrm{SiCl}$ (4 equiv) followed by addition of KHMDS (usually 4 equiv) in THF at $-78^{\circ} \mathrm{C}$. The resulting silyl ketene acetals of $(Z)$-configuration $\mathbf{5 7 a - 1}$, arising from O-silylation of the corresponding chelated potassium enolates [60], underwent an efficient [3,3]-sigmatropic rearrangement upon warming to room temperature. After an acidic work-up and treatment of the crude carboxylic acids with trimethylsilyldiazomethane, the resulting $\alpha$-alkoxy methyl esters 


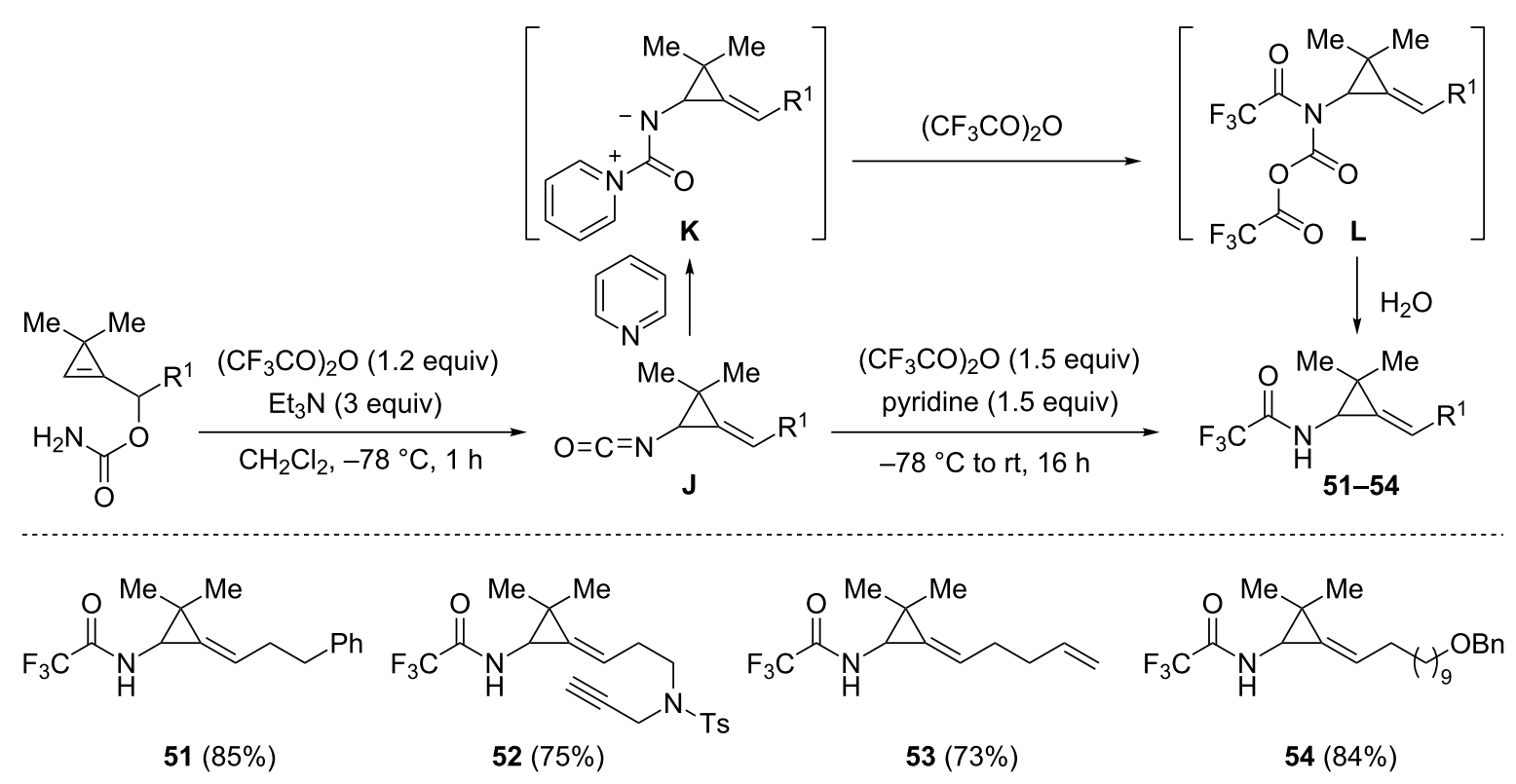

Scheme 19: Formation of alkylidene[( $N$-trifluoroacetylamino $)$ cyclopropanes] 51-54.

$$
\text { (10\%)/C (5 mol \%) }
$$

Scheme 20: Diastereoselective hydrogenation of alkylidenecyclopropane 51.

$\mathbf{5 8 a}-\mathbf{l}$, incorporating an alkylidenecyclopropane moiety, were obtained as single detectable diastereomers [61]. As in the previously discussed [3,3]-sigmatropic rearrangements, the observed stereochemical outcome was in agreement with a sixmembered chair-like transition state model TS6 in which the substituent at the $\alpha$-position of the oxygen atom (C4) preferentially occupies a pseudo-equatorial position. The scope of the reaction is rather broad as the substituent at $\mathrm{C} 4$ can be an alkyl chain, possibly incorporating a protected alcohol, as illustrated with the formation of alkylidenecyclopropanes 58a (86\%), 58b $(60 \%)$ and $58 \mathrm{c}(84 \%)$. It is worth mentioning that despite the use of a strong base (KHMDS) and the acidity of the "vinylic" protons of cyclopropenes which is comparable to that of a terminal alkyne [62], cyclopropenylcarbinyl glycolates devoid of substituents at $\mathrm{C} 2$ were viable substrates. The sequence allowed access to benzylidenecyclopropane 58d (93\%) and to (arylmethylene)cyclopropane 58e in excellent yield (90\%), despite the presence of the electron-withdrawing trifluoromethyl substituent at the para-position of the aromatic ring. Some heteroaromatic groups were also tolerated at $\mathrm{C} 4$, as shown with the synthesis of (heteroarylmethylene) cyclopropanes $\mathbf{5 8 f}-\mathbf{h}$ (60-72\%). The gem-dimethyl substitution at C3 which was common to the previous cyclopropenylcarbinyl glycolates 56a-h, could be suppressed and the corresponding alkylidenecyclopropane 58i was produced in excellent yield (94\%). More sterically hindered substituents were tolerated at C3, as illustrated with the isolation of the spirocyclic compounds $\mathbf{5 8 j}$ (60\%) and 58k (77\%), and alkylidenecyclopropane $\mathbf{5 8 1}$ possessing a fully substituted three-membered ring was also formed in excellent yield (96\%). That the Ireland-Claisen rearrangement of cyclopropenylcarbinyl glycolates proceeded with chirality transfer was also verified in the case of alkylidenecyclopropanes 58a and 58i which were obtained with optical purities (ee $=87 \%$ and ee $=97 \%$, respectively) identical to those of the corresponding enantioenriched precursors $(R)-\mathbf{5 6}$ a and (R)-56i (Scheme 21) [61].

The addition of a cyclopropenyllithium to an aldehyde is arguably the most widely used method to access cyclopropenylcarbinols but Gevorgyan et al. disclosed an interesting organocatalytic route to cyclopropenylcarbinols possessing gem-diester substitution at C3 [63]. As illustrated with the 

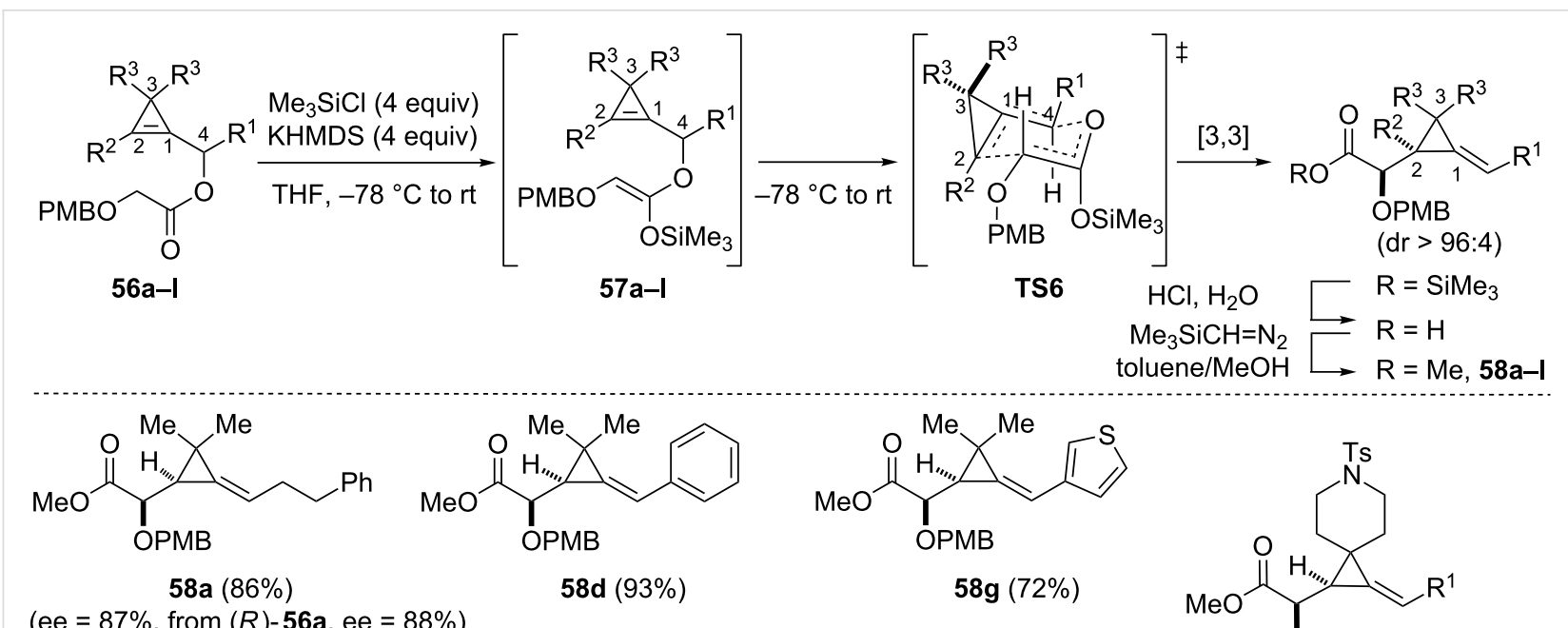

$(\mathrm{ee}=87 \%$, from $(R)-56 \mathrm{a}$, ee $=88 \%)$<smiles>COC(=O)C(O[R16](C)(C)C)C1C(=CCC[OH+])C1(C)C</smiles>

$58 b(60 \%)$<smiles>COC(=O)C(O[R16](=O)c1ccccc1)C1C(=CCOCc2ccccc2)C1(C)C</smiles>

$58 \mathrm{c}(84 \%)$<smiles>COC(=O)C(OC)C1C(=Cc2ccc(C(F)(F)F)cc2)C1(C)C</smiles>

$58 \mathrm{e}(90 \%)$<smiles>CCOC(C(=O)OC)[C@H]1C(=Cc2cccnc2)C1(C)C</smiles>

$58 f(67 \%)^{b}$<smiles>CCOC(C(=O)OC)C1C(=Cc2cnn(C)c2)C1(C)C</smiles>

$58 \mathrm{~h}(60 \%)^{\mathrm{b}}$<smiles>[R1]C=C1C(C(O[R15])OC(C)=O)C12CCN([135I])CC2</smiles>

58j, $\mathrm{R}^{1}=\mathrm{CH}_{2} \mathrm{OBn}(60 \%)^{\mathrm{a}}$

58k, $\mathrm{R}^{1}=p-\mathrm{MeO}-\mathrm{C}_{6} \mathrm{H}_{4}(77 \%)^{\mathrm{a}}$<smiles>COC(=O)C(OC(C)(C)C)C1(C)C/C1=C\CCc1ccccc1</smiles>

$58 \mathbf{i}(94 \%)$<smiles>COC(=O)C(OC)C1(C)C(=CCCc2ccccc2)C1(C)C</smiles>

$58 \mathrm{I}(96 \%)$

$(\mathrm{ee}=97 \%$, from $(R)-56 \mathrm{i}, \mathrm{ee}=97 \%)$

a overall yield from the corresponding cyclopropenylcarbinol;

benolization carried out with KHMDS (2 equiv) and $\mathrm{Me}_{3} \mathrm{SiCl}$ (2 equiv)

Scheme 21: Ireland-Claisen rearrangement of cyclopropenylcarbinyl glycolates 56a-I.

preparation of alcohol $\mathbf{6 0}$, the strategy relies on a sila-Morita-Baylis-Hillman reaction between cyclopropenylsilane $\mathbf{5 9}$ and 3-phenylpropanal catalyzed by electron-rich tris(2,4,6trimethoxyphenyl)phosphine (TTMPP) [63]. After desilylation, cyclopropenylcarbinol $\mathbf{6 0}$ was converted into glycolate $\mathbf{6 1}$ under standard conditions and the latter ester was engaged in the Ireland-Claisen rearrangement. Because the gem-diester substitution at $\mathrm{C} 3$ increased the acidity of the proton at $\mathrm{C} 2$ in substrate 61 [64], silylation of that position took place under the reaction conditions prior to the Ireland-Claisen rearrangement which eventually produced alkylidenecyclopropane 62 (56\%) with high diastereoselectivity. The trimethylsilyl substituent at $\mathrm{C} 2$ could then be easily removed by treatment of $\mathbf{6 2}$ with tetrabutylammonium fluoride under buffered conditions $(\mathrm{AcOH}$, THF, $\left.0{ }^{\circ} \mathrm{C}\right)$ to afford alkylidenecyclopropane 63 (92\%, Scheme 22) [61].

The Ireland-Claisen rearrangement was then extended to a challenging class of cyclopropylcarbinyl glycolates possessing gemdifluoro substitution at C3 [65]. Gem-difluorocyclopropenes are accessible by difluorocyclopropenation of alkynes with difluorocarbene but these compounds display poor stability in most cases and readily undergo hydrolysis into cyclopropenones which possess an aromatic character [66,67]. Gem-difluorocyclopropenylcarbinyl glycolates $\mathbf{6 5 a}-\mathbf{n}$ were prepared by slow addition of an excess of trimethylsilyl fluorosulfonyldifluoroacetate (TFDA) [68] to a solution of propargyl glycolates 64a-n containing $\mathrm{NaF}$ in diglyme at $120^{\circ} \mathrm{C}$. Difluorocyclopropene 65a could be purified by flash chromatography on silica gel and was isolated in $86 \%$ yield but this compound rapidly underwent decomposition upon storage. The instability of glycolates $65 \mathbf{a}-\mathbf{n}$ was a critical issue which was solved by carrying those intermediate compounds directly in the sigmatropic rearrangement. Byproducts arising from the difluorocyclopropenation reaction $\left(\mathrm{CO}_{2}, \mathrm{SO}_{2}\right.$ and $\left.\mathrm{Me}_{3} \mathrm{SiF}\right)$ were simply removed by argon sparging of the reaction mixture and the Ireland-Claisen rearrangement was then triggered by addition of $\mathrm{Me}_{3} \mathrm{SiCl}$ (4 equiv) and KHMDS ( 4 equiv), (THF, $-78^{\circ} \mathrm{C}$ to rt). Subsequent hydrolysis and treatment with trimethylsilyldiazomethane afforded the corresponding $\alpha$-alkoxy methyl esters $66 \mathbf{a}-\mathbf{h}$, and $66 \mathbf{k}-\mathbf{n}$ 


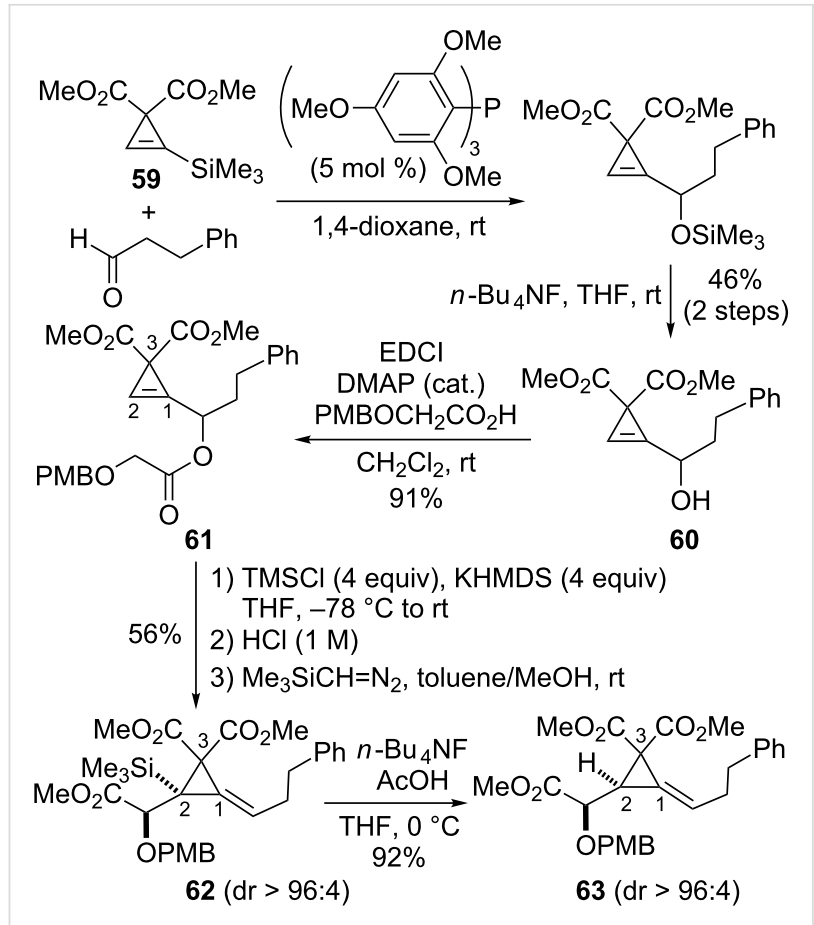

Scheme 22: Synthesis and Ireland-Claisen rearrangement of glycolate 61 possessing gem-diester substitution at C3.

possessing a 3,3-difluoroalkylidenecyclopropane scaffold. This two-step difluorocyclopropenation-Ireland-Claisen rearrangement sequence was applied to propargyl glycolates $64 \mathbf{a}-\mathbf{e}$ possessing a phenyl, a $p$-methoxyphenyl, a $p$-bromophenyl, an $o$-chlorophenyl or a 1-naphthyl substituent at the acetylenic position, as illustrated with the formation of compounds $66 \mathbf{a}-\mathbf{e}$ (63-76\%, two steps from the corresponding propargylic glycolates). Not surprisingly, chirality transfer (from $\mathrm{C} 4$ to $\mathrm{C} 2$ ) also occurred in the Ireland-Claisen rearrangement, as demonstrated by the formation of $(-)-66 \mathbf{b}($ ee $=95 \%)$ from optically enriched $(S)$-64b (ee = 96\%). Heteroaromatic groups (indol-3-yl and 3-thienyl) were tolerated at the acetylenic position and the corresponding glycolates $64 \mathrm{f}$ and $\mathbf{6 4 g}$ led to compounds $66 \mathrm{f}$ and $\mathbf{6 6 g}$ in $70 \%$ yield. A $p$-acetylphenyl group was compatible as shown with the isolation of alkylidenecyclopropane $\mathbf{6 6 h}$ (65\%) but it should be noted that the electron-withdrawing methyl ketone was converted to a trimethylsilyl enol ether upon treatment with $\mathrm{KHMDS} / \mathrm{Me}_{3} \mathrm{SiCl}$. By contrast, an electron-withdrawing $p$-nitrophenyl group was not tolerated because the intermediate cyclopropene $\mathbf{6 5 i}$ underwent decomposition under the reaction conditions of the Ireland-Claisen rearrangement, presumably because of competitive deprotonation at $\mathrm{C} 4$. A phenyl substituent was incompatible at $\mathrm{C} 4$ as the corresponding substrate $\mathbf{6 5 j}$ decomposed upon treatment with KHMDS/ $\mathrm{Me}_{3} \mathrm{SiCl}$. This was explained by a competitive abstraction of the hydrogen at $\mathrm{C} 4$ by the base thereby resulting in side reactions. However, various alkyl substituents could be present at the propargylic position in glycolates $64 \mathbf{k}-\mathbf{n}$ which afforded the corresponding rearranged compounds $66 \mathbf{k}-\mathbf{n}$ in moderate yields (40-61\%, Scheme 23) [65].

With the goal of accessing $\alpha$-amino acid derivatives incorporating an alkylidenecyclopropane, the Ireland-Claisen rearrangement of $N, N$-diBoc glycinates $67 \mathbf{a}$ and $67 \mathbf{b}$ was explored. The reaction conditions were essentially the same as those described previously with glycolates 56a-l except that LiHMDS was used as the base in the enolization step [69]. The (Z)-silyl ketene acetals $68 \mathrm{a}$ and $\mathbf{6 8 b}$ were generated, in agreement with previous results disclosed by Carbery et al. with allylic $N, N$ diBoc glycinates [69], and underwent a Ireland-Claisen rearrangement to afford $N, N$-diBoc $\alpha$-amino esters 69a (78\%) and 69b (91\%) in good yields and with high diastereoselectivity [61]. Although cleavage of the two Boc groups could not be achieved cleanly upon exposure of $69 \mathrm{~b}$ to a large excess of trifluoroacetic acid, this operation could be accomplished in a sequential manner by addition of trifluoroacetic acid (2 equiv, $\mathrm{CH}_{2} \mathrm{Cl}_{2}, 0{ }^{\circ} \mathrm{C}$ ) and then by treatment of the resulting $N$-Boc carbamate 70 (97\%) with trimethylsilyl triflate in the presence of 2,6-lutidine to generate $\alpha$-amino ester 71 (99\%, Scheme 24) [61].

Alkylidenecyclopropanes resulting from the Ireland-Claisen rearrangement of cyclopropenylcarbinyl glycolates and glycinates can serve as useful precursors of other classes of functionalized cyclopropanes. As shown previously with alkylidene(aminocyclopropane) derivatives, diastereoselective hydrogenation reactions of alkylidenecyclopropanes possessing a single substituent at $\mathrm{C} 2$ can be carried out with complementary face selectivities, depending on the conditions and substrates. Thus, the hydrogenation of 58 a catalyzed by $\mathrm{Rh} / \mathrm{C}$ occurred on the less hindered face of the alkene and gave rise to cyclopropyl $\alpha$-alkoxy ester $\mathbf{7 2}$ as a single detectable diastereomer. When $\mathrm{Pd} / \mathrm{C}$ was used as the catalyst, cleavage of the PMB group took place concomitantly and the $\alpha$-hydroxy ester $\mathbf{7 3}$ arising from addition of hydrogen on the less-hindered face of the olefin was obtained predominantly $\left(\mathbf{7 3} / \mathbf{7 3}^{\prime}=90: 10\right)$ albeit with lower diastereocontrol compared to the protected alcohol 58a. Cleavage of the PMB ether in 58a was achieved purposely with DDQ so that a hydroxy-directed hydrogenation of the resulting $\alpha$-hydroxy ester $\mathbf{7 4}$ could be carried out in the presence of Crabtree's catalyst [58], thereby allowing access to cyclopropylcarbinol 73' with high diastereoselectivity $(\mathbf{7 3}, / 73=97: 3$, Scheme 25).

By taking advantage of the directing effect of a hydroxy group, diastereoselective hydrogenations of alkylidenecyclopropanes possessing two substituents at $\mathrm{C} 2$ could be achieved. As illustrated for alkylidene(gem-difluorocyclopropane) 66a, cleavage 

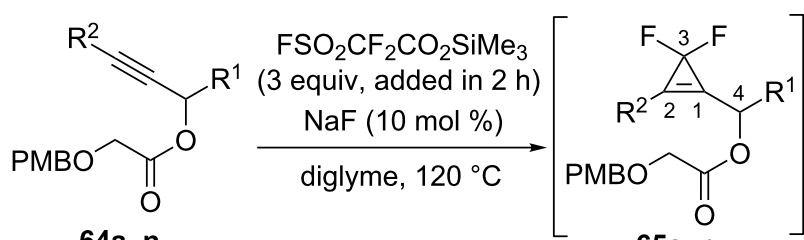

1) dilution with THF and argon sparging

2) $\mathrm{TMSCl}$ (4 equiv), KHMDS (4 equiv)

THF, $-78^{\circ} \mathrm{C}$ to it

$\left.\underbrace{R_{1, m}^{2}}_{O P M B}\right|_{2} ^{F_{1}^{2}} R_{4}^{1}$

64a-n

65a-n

3) $\mathrm{NH}_{4} \mathrm{Cl}, \mathrm{H}_{2} \mathrm{O}$

4) $\mathrm{TMSCHN}_{2}$, toluene/MeOH (1:1), rt

66a-n
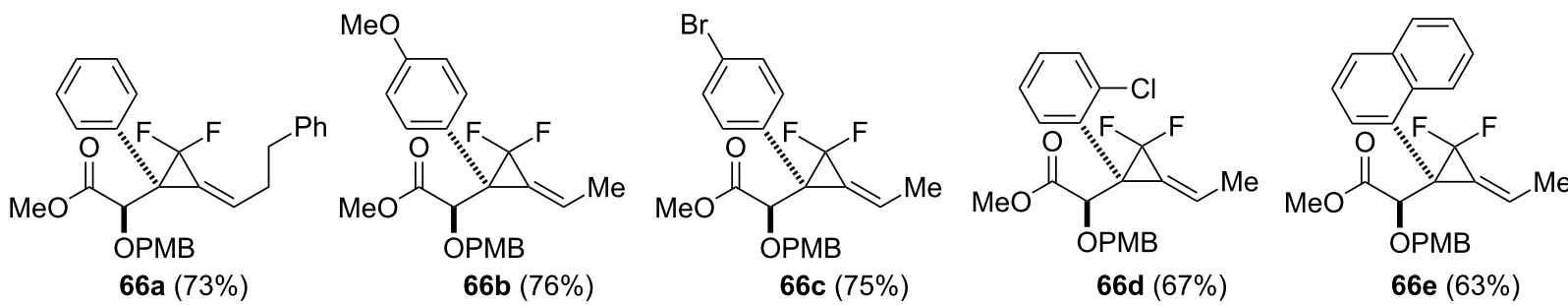

$[\mathrm{ee}=95 \%$ from $(S)-64 \mathrm{~b}(\mathrm{ee}=96 \%)]$

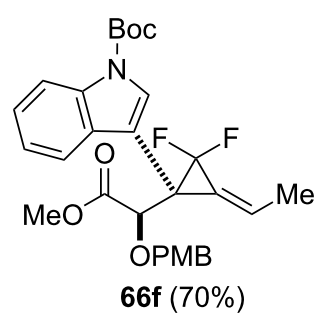<smiles>[R16]OC(C(=O)OC)C1(C)C(=CCCc2ccccc2)C1(F)F</smiles>

66k $(61 \%)$
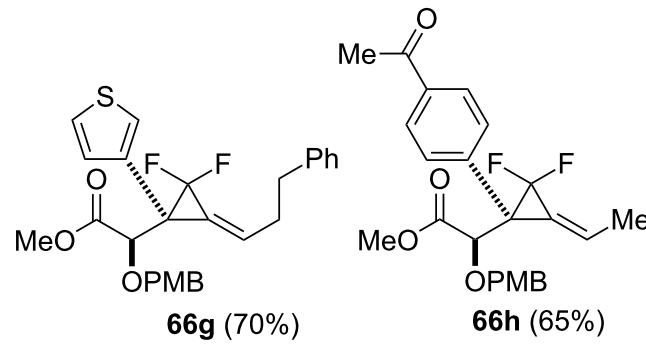

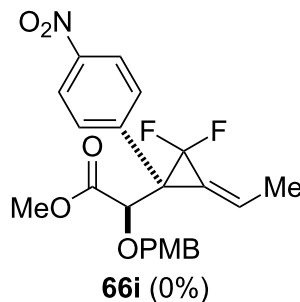

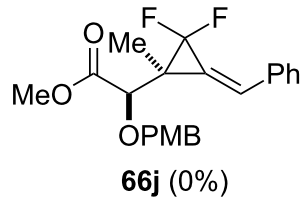

66j $(0 \%)$

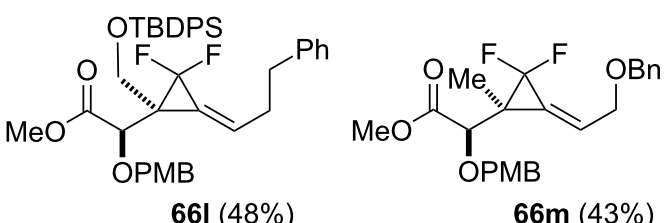
TBDPSO<smiles>COCCOC(C(=O)OC)[C@@]1(CCOCc2ccccc2)C(=CCOc2ccccc2)C1(F)F</smiles>

Scheme 23: Synthesis of alkylidene(gem-difluorocyclopropanes) $66 \mathrm{a}-\mathbf{h}$, and $66 \mathrm{k}-\mathbf{n}$ from propargyl glycolates $64 a-n$<smiles>[R]C(OC(=O)CNC(=O)OCc1ccccc1)C1CC1(C)C</smiles>

67a, $\mathrm{R}^{1}=\left(\mathrm{CH}_{2}\right)_{2} \mathrm{Ph}$

67b, $\mathrm{R}^{1}=\mathrm{Ph}$

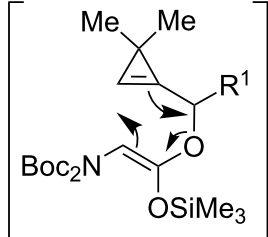

68a, $\mathrm{R}^{1}=\left(\mathrm{CH}_{2}\right)_{2} \mathrm{Ph}$

68b, $\mathrm{R}^{1}=\mathrm{Ph}$

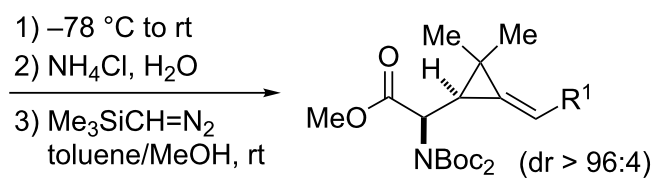

69a, $\mathrm{R}^{1}=\left(\mathrm{CH}_{2}\right)_{2} \mathrm{Ph}(78 \%)$

$69 \mathrm{~b}, \mathrm{R}^{1}=\mathrm{Ph}$

$(91 \%)$<smiles>COC(=O)C(N)C1C(=Cc2ccccc2)C1(C)C</smiles>

Scheme 24: Ireland-Claisen rearrangement of $N, N$-diBoc glycinates $67 \mathbf{a}$ and $67 \mathbf{b}$.

of the PMB group and subsequent hydrogenation of the resulting $\alpha$-hydroxy ester 75 (75\%) in the presence of Crabtree's catalyst delivered the gem-difluorocyclopropane $76(91 \%)$ as a single diastereomer. The reduction of ester $\mathbf{7 6}$ with $\mathrm{LiAlH}_{4}$ and oxidative cleavage of the resulting 1,2-diol with $\mathrm{NaIO}_{4}$ delivered the highly substituted gem-difluorocyclopropanecarboxaldehyde $77(72 \%)$ possessing a quaternary stereocenter (Scheme 26) [65]. 


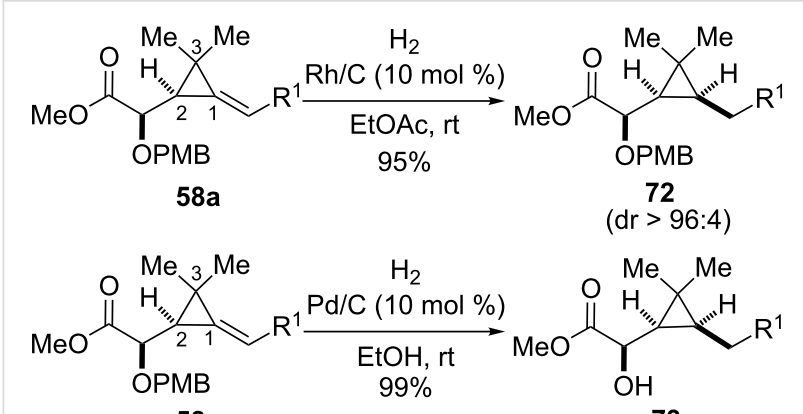

$58 a$

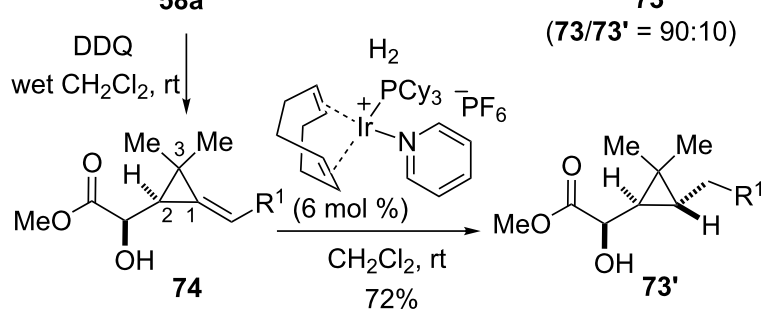

$\mathrm{R}^{1}=\left(\mathrm{CH}_{2}\right)_{2} \mathrm{Ph}(2$ steps from $58 \mathrm{a})$

$\left(73^{\prime} / 73=97: 3\right)$

Scheme 25: Diastereoselective hydrogenation of alkylidenecyclopropanes $58 \mathrm{a}$ and $\mathbf{7 4}$.

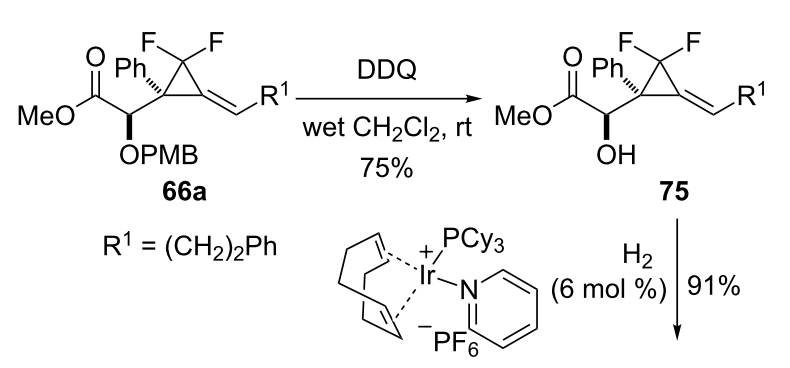<smiles>[R]C[C@@H]1C(F)(F)[C@@]1([2H])C=O</smiles>

77

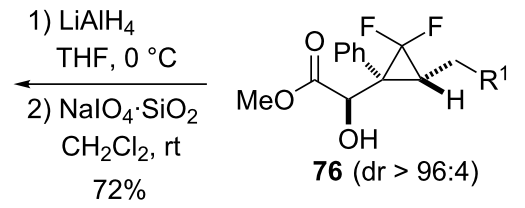

Scheme 26: Synthesis of functionalized gem-difluorocyclopropanes 76 and 77 from alkylidenecyclopropane $\mathbf{6 6 a}$.

Other examples of post-functionalization involve iodolactonization reactions which were applied to $\alpha$-hydroxy esters $\mathbf{7 4}$ and $\mathbf{7 5}$ using $N$-iodosuccinimide $\left(\mathrm{MeCN} / \mathrm{H}_{2} \mathrm{O}, 50{ }^{\circ} \mathrm{C}\right)$ [70], or to the $N$-benzylamine generated from $\alpha$-amino ester 71 (by reductive animation with benzaldehyde) in the presence of $\mathrm{I}_{2}$ and $\mathrm{K}_{2} \mathrm{CO}_{3}$ $(\mathrm{MeCN}, \mathrm{rt})$ [71]. These iodocyclizations led to the oxabicyclic compounds 78 (98\%) and 79 (99\%), and to the azabicyclic product $80(45 \%)$, respectively, with high diastereoselectivities (Scheme 27) [61,65].

\section{Conclusion}

In recent years, [2,3]- and [3,3]-sigmatropic rearrangements of cyclopropenylcarbinol derivatives have emerged as useful tools
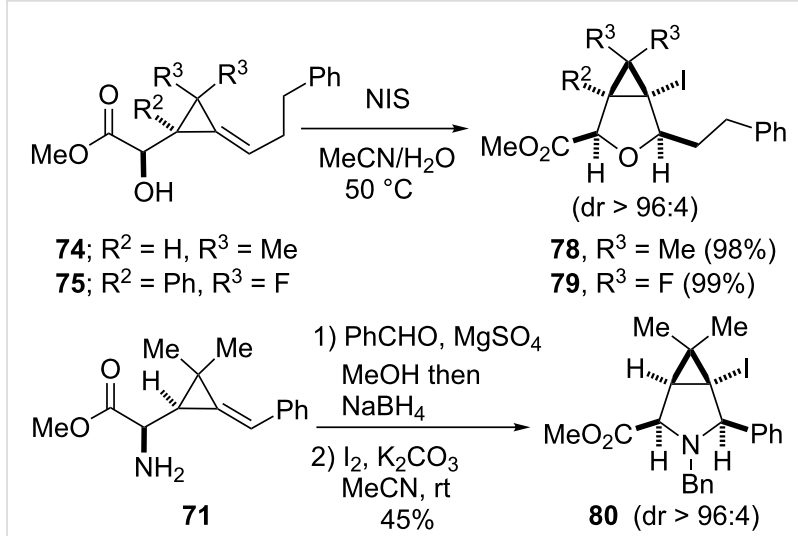

Scheme 27: Access to oxa- and azabicyclic compounds 78-80.

for the stereoselective synthesis of a wide variety of alkylidenecyclopropanes, substituted by heteroatoms (P, O, N, F) and/or incorporating valuable functional groups ( $\alpha$-alkoxy or $\alpha$-amino acid derivatives) which are potentially useful for further functionalization. The reactivity of heterosubstituted/ functionalized alkylidenecyclopropanes arising from those sigmatropic rearrangements, which are not easily accessible by other strategies, has only been sparingly investigated to date but the results summarized in this short review, in conjunction with the very rich chemistry of alkylidenecyclopropanes, may stimulate further investigations in this particular area.

\section{Acknowledgements}

One of us (G. E.) thanks Diverchim for a CIFRE grant.

\section{ORCID ${ }^{\circledR}$ iDs}

Christophe Meyer - https://orcid.org/0000-0003-3420-5584 Janine Cossy - https://orcid.org/0000-0001-8746-9239

\section{References}

1. Rubin, M.; Rubina, M.; Gevorgyan, V. Chem. Rev. 2007, 107, 3117-3179. doi:10.1021/cr050988

2. Marek, I.; Simaan, S.; Masarwa, A. Angew. Chem., Int. Ed. 2007, 46, 7364-7376. doi:10.1002/anie.200604774

3. Zhu, Z.-B.; Wei, Y.; Shi, M. Chem. Soc. Rev. 2011, 40, 5534-5563. doi:10.1039/c1cs15074j

4. Miege, F.; Meyer, C.; Cossy, J. Beilstein J. Org. Chem. 2011, 7, 717-734. doi:10.3762/bjoc.7.82

5. Vicente, R. Synthesis 2016, 48, 2343-2360. doi:10.1055/s-0035-1561644

6. Dian, L.; Marek, I. Chem. Rev. 2018, 118, 8415-8434 doi:10.1021/acs.chemrev.8b00304

7. Salaün, J. Cyclopropane Derivatives and their Diverse Biological Activities. In Small Ring Compounds in Organic Synthesis VI. Topics in Current Chemistry; Meijere, A., Ed.; Springer: Berlin, Heidelberg, 2000; Vol. 207, pp 1-67. doi:10.1007/3-540-48255-5_1

8. Donaldson, W. A. Tetrahedron 2001, 57, 8589-8627. doi:10.1016/s0040-4020(01)00777-3 
9. Talele, T. T. J. Med. Chem. 2016, 59, 8712-8756. doi:10.1021/acs.jmedchem.6b00472

10. Lautens, M.; Klute, W.; Tam, W. Chem. Rev. 1996, 96, 49-92. doi:10.1021/cr950016l

11. Brandi, A.; Goti, A. Chem. Rev. 1998, 98, 589-636. doi:10.1021/cr940341t

12. Nakamura, I.; Yamamoto, Y. Adv. Synth. Catal. 2002, 344, 111-129. doi:10.1002/1615-4169(200202)344:2<111::aid-adsc111>3.0.co;2-0

13. Brandi, A.; Cicchi, S.; Cordero, F. M.; Goti, A. Chem. Rev. 2014, 114, 7317-7420. doi:10.1021/cr400686j

14. Pellissier, H. Tetrahedron 2014, 70, 4991-5031. doi:10.1016/j.tet.2014.04.057

15. Audran, G.; Pellissier, H. Adv. Synth. Catal. 2010, 352, 575-608. doi:10.1002/adsc.200900872

16. Köster, R.; Arora, S.; Binger, P. Angew. Chem., Int. Ed. Engl. 1969, 8, 205-206. doi:10.1002/anie.196902052

17. Vincens, M.; Dumont, C.; Vidal, M. Tetrahedron 1981, 37, 2683-2694. doi:10.1016/s0040-4020(01)98975-6

18. Sang, R.; Yang, H.-B.; Shi, M. Tetrahedron Lett. 2013, 54, 3591-3594. doi:10.1016/j.tetlet.2013.04.076

19. Wiberg, K. B.; Fenoglio, R. A. J. Am. Chem. Soc. 1968, 90, 3395-3397. doi:10.1021/ja01015a018

20. Bach, R. D.; Dmitrenko, O. J. Am. Chem. Soc. 2004, 126, 4444-4452. doi:10.1021/ja036309a

21. Shibuya, A.; Okada, M.; Nakamura, Y.; Kibashi, M.; Horikawa, H.; Taguchi, T. Tetrahedron 1999, 55, 10325-10340. doi:10.1016/s0040-4020(99)00588-8

22. Weatherhead-Kloster, R. A.; Corey, E. J. Org. Lett. 2006, 8, 171-174. doi:10.1021/ol052752+

23. Padwa, A.; Wannamaker, M. W. Tetrahedron 1991, 47, 6139-6156. doi:10.1016/s0040-4020(01)86547-9

24. Zohar, E.; Stanger, A.; Marek, I. Synlett 2005, 2239-2241. doi:10.1055/s-2005-872247

25. Baumann, A. N.; Music, A.; Karaghiosoff, K.; Didier, D. Chem. Commun. 2016, 52, 2529-2532. doi:10.1039/c5cc09904h

26. Babin, D.; Pilorge, F.; Delbarre, L. M.; Demoute, J. P. Tetrahedron 1995, 51, 9603-9610. doi:10.1016/0040-4020(95)00535-g

27. Nüske, H.; Bräse, S.; de Meijere, A. Synlett 2000, 1467-1469. doi:10.1055/s-2000-7627

See for the addition of malonates to $\pi$-allyl-palladium complexes derived cyclopropenylmethyl acetates leading to the cyclopropene isomer except in the case of one tertiary acetate.

28. Yang, Z.; Xie, X.; Fox, J. M. Angew. Chem., Int. Ed. 2006, 45, 3960-3962. doi:10.1002/anie.200600531

29. Xie, X.; Yang, Z.; Fox, J. M. J. Org. Chem. 2010, 75, 3847-3850. doi:10.1021/jo1002938

30. Xie, X.; Fox, J. M. Synthesis 2013, 45, 1807-1814. doi:10.1055/s-0033-1338876

31. Simaan, S.; Masarwa, A.; Bertus, P.; Marek, I. Angew. Chem., Int. Ed. 2006, 45, 3963-3965. doi:10.1002/anie.200600556

32. Simaan, S.; Marek, I. Chem. Commun. 2009, 292-294. doi:10.1039/b817710d

See for the copper-catalyzed reduction of secondary cyclopropenylcarbinols which has also been reported.

33. Simaan, S.; Masarwa, A.; Zohar, E.; Stanger, A.; Bertus, P.; Marek, I. Chem. - Eur. J. 2009, 15, 8449-8464. doi:10.1002/chem.200901074

34. Masarwa, A.; Stanger, A.; Marek, I. Angew. Chem., Int. Ed. 2007, 46, 8039-8042. doi:10.1002/anie.200702713
35. Baird, M. S.; Hussain, H. H.; Nethercott, W. J. Chem. Soc., Perkin Trans. 1 1986, 1845-1853. doi:10.1039/p19860001845

36. Liron, F.; Knochel, P. Chem. Commun. 2004, 304-305. doi:10.1039/b313979d

See for the stereoselective [2,3]-sigmatropic rearrangement of acyclic allylic phosphinites.

37. Rubina, M.; Woodward, E. W.; Rubin, M. Org. Lett. 2007, 9, 5501-5504. doi:10.1021/ol702473s

38. Muthuramu, K.; Ramamurthy, V. J. Chem. Soc., Chem. Commun. 1980, 243-244. doi:10.1039/c39800000243

39. Andrews, S. D.; Day, A. C. Chem. Commun. 1966, 667-669. doi:10.1039/c19660000667

40. Maier, G.; Straßer, M. Tetrahedron Lett. 1966, 7, 6453-6456. doi:10.1016/s0040-4039(00)76125-9

41. Seraya, E.; Slack, E.; Ariafard, A.; Yates, B. F.; Hyland, C. J. T. Org. Lett. 2010, 12, 4768-4771. doi:10.1021/ol101862u

42. Archambeau, A.; Nguyen, D.-V.; Meyer, C.; Cossy, J. Chem. - Eur. J. 2016, 22, 6100-6110. doi:10.1002/chem.201505063

43. Obame, G.; Brémond, P.; Pannecouque, C.; Audran, G. Synthesis 2013, 45, 2612-2618. doi:10.1055/s-0033-1339311

44. Li, K.; Du, W.; Que, N. L. S.; Liu, H.-w. J. Am. Chem. Soc. 1996, 118, 8763-8764. doi:10.1021/ja960822p

45. Zhao, Z.; Liu, H.-w. J. Org. Chem. 2002, 67, 2509-2514. doi:10.1021/jo010994r

46. Kawanaka, Y.; Kobayashi, K.; Kusuda, S.; Tatsumi, T.; Murota, M.; Nishiyama, T.; Hisaichi, K.; Fujii, A.; Hirai, K.; Naka, M.; Komeno, M.; Odagaki, Y.; Nakai, H.; Toda, M. Bioorg. Med. Chem. 2003, 11 , 1723-1743. doi:10.1016/s0968-0896(03)00034-8

47. Overman, L. E.; Carpenter, N. E. Org. React. 2005, 66, 1-107. doi:10.1002/0471264180.or066.01

48. Howard, J. K.; Amin, C.; Lainhart, B.; Smith, J. A.; Rimington, J.; Hyland, C. J. T. J. Org. Chem. 2014, 79, 8462-8468. doi:10.1021/jo501423u

49. The reaction conditions are those indicated accurately in the experimental section.

50. Nishikawa, T.; Urabe, D.; Tomita, M.; Tsujimoto, T.; Iwabuchi, T.; Isobe, M. Org. Lett. 2006, 8, 3263-3265. doi:10.1021/ol061123c

51. Shinkevich, E.; Deblander, J.; Matthijs, S.; Jacobs, J.; De Kimpe, N.; Tehrani, K. A. Org. Biomol. Chem. 2011, 9, 538-548. doi:10.1039/c0ob00391c

52. Gallego, G.; Ariafard, A.; Tran, K.; Sandoval, D.; Choi, L.; Chen, Y.-H.; Yates, B. F.; Tao, F.-M.; Hyland, C. J. T. Org. Biomol. Chem. 2011, 9, 3359-3363. doi:10.1039/c0ob01046d

53. Ernouf, G.; Brayer, J.-L.; Folléas, B.; Demoute, J.-P.; Meyer, C.; Cossy, J. Chem. - Eur. J. 2018, 24, 15104-15111. doi:10.1002/chem.201803231

54. See for a review. Nocquet, P.-A.; Henrion, S.; Macé, A.; Carboni, B.; Villalgordo, J. M.; Carreaux, F. Eur. J. Org. Chem. 2017, 1295-1307. doi:10.1002/ejoc.201601316

55. Roy, S.; Spino, C. Org. Lett. 2006, 8, 939-942. doi:10.1021/ol053061g

56. Henrion, S.; Carboni, B.; Cossío, F. P.; Roisnel, T.; Villalgordo, J. M.; Carreaux, F. J. Org. Chem. 2016, 81, 4633-4644. doi:10.1021/acs.joc.6b00505

57. Schuemacher, A. C.; Hoffmann, R. W. Synthesis 2001, 243-246. doi:10.1055/s-2001-10813

58. Crabtree, R. H.; Davis, M. W. J. Org. Chem. 1986, 51, 2655-2661. doi:10.1021/jo00364a007

59. Nubbenmeyer, U.; Hiersemann, M., Eds. The Claisen Rearrangement. Methods and Applications; Wiley-VCH: Weinheim, Germany, 2007. 
60. Gould, T. J.; Balestra, M.; Wittman, M. D.; Gary, J. A.; Rossano, L. T.; Kallmerten, J. J. Org. Chem. 1987, 52, 3889-3901.

doi:10.1021/jo00226a032

61. Ernouf, G.; Brayer, J.-L.; Folléas, B.; Demoute, J.-P.; Meyer, C.; Cossy, J. Org. Lett. 2015, 17, 3786-3789.

doi:10.1021/acs.orglett.5b01759

62. Fattahi, A.; McCarthy, R. E.; Ahmad, M. R.; Kass, S. R. J. Am. Chem. Soc. 2003, 125, 11746-11750. doi:10.1021/ja035725s

63. Chuprakov, S.; Malyshev, D. A.; Trofimov, A.; Gevorgyan, V. J. Am. Chem. Soc. 2007, 129, 14868-14869. doi:10.1021/ja077437s

64. Zrinski, I.; Eckert-Maksić, M. Synth. Commun. 2003, 33, 4071-4077. doi:10.1081/scc-120026348

65. Ernouf, G.; Brayer, J.-L.; Folléas, B.; Demoute, J.-P.; Meyer, C.; Cossy, J. J. Org. Chem. 2017, 82, 3965-3975. doi:10.1021/acs.joc.7b00197

66. Bessard, Y.; Schlosser, M. Tetrahedron 1991, 47, 7323-7328. doi:10.1016/s0040-4020(01)89734-9

67. Cheng, Z.-L.; Chen, Q.-Y. Chin. J. Chem. 2006, 24, 1219-1224. doi:10.1002/cjoc.200690227

68. Tian, F.; Kruger, V.; Bautista, O.; Duan, J.-X.; Li, A.-R.; Dolbier, W. R.; Chen, Q.-Y. Org. Lett. 2000, 2, 563-564. doi:10.1021/ol0055622

69. Tellam, J. P.; Carbery, D. R. J. Org. Chem. 2010, 75, 7809-7821. doi:10.1021/jo1017124

70. Wang, B.-Y.; Huang, J.-W.; Liu, L.-P.; Shi, M. Synlett 2005, 421-424. doi:10.1055/s-2004-837218

71. Fu, W.; Huang, X. Tetrahedron Lett. 2008, 49, 562-565. doi:10.1016/j.tetlet.2007.11.068

\section{License and Terms}

This is an Open Access article under the terms of the Creative Commons Attribution License (http://creativecommons.org/licenses/by/4.0). Please note that the reuse, redistribution and reproduction in particular requires that the authors and source are credited.

The license is subject to the Beilstein Journal of Organic Chemistry terms and conditions:

(https://www.beilstein-journals.org/bjoc)

The definitive version of this article is the electronic one which can be found at: doi:10.3762/bjoc. 15.29 